\title{
The Illusion of Sustainability
}

\author{
Michael Kremer and Edward Miguel
}

CID Working Paper No. 112

November 2004

(C) Copyright 2004 Michael Kremer, Edward Miguel and the President and Fellows of Harvard College
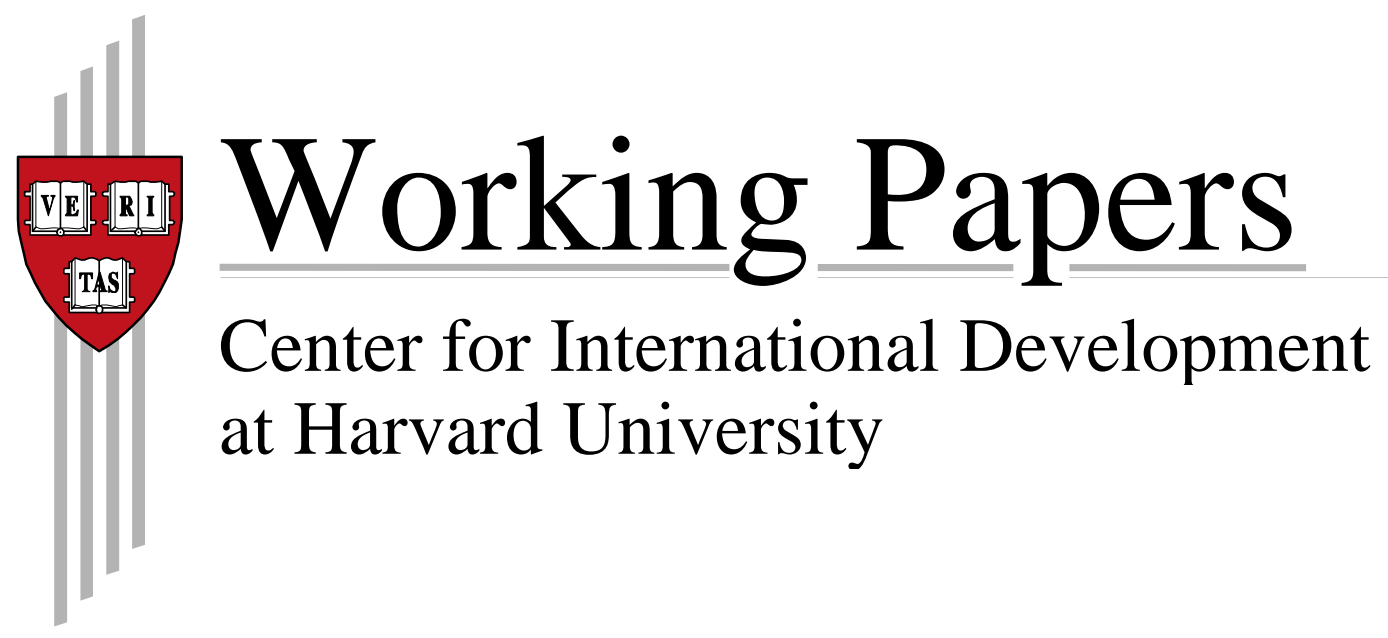


\title{
The Illusion of Sustainability*
}

Michael Kremer

Harvard University, The Brookings Institution, The Center for Global Development and NBER
Edward Miguel

University of California, Berkeley and NBER

\author{
CID Working Paper No. 112 \\ November 2004
}

\begin{abstract}
Rather than provide development assistance indefinitely, foreign aid donors increasingly seek to help communities sustainably provide local public goods themselves. We examine various strategies for sustainably fighting intestinal worms through voluntary local mobilization. Intestinal worms affect one in four people worldwide, but can be controlled by taking medicine twice annually. Since much of the resulting treatment benefit comes through reduced disease transmission, standard public finance analysis provides a rationale for subsidized treatment. Randomized evaluations suggest several efforts to replace subsidies with sustainable worm control measures were ineffective. A drug cost recovery program reduced take-up by $80 \%$. A mobilization intervention designed to boost drug take up failed. Health education did not affect behavior. People were less likely to take drugs if randomly exposed to more information through their social network. In this context, using external interventions to promote sustainable voluntary provision of local public goods (like worm control) appears unrealistic.
\end{abstract}

Keywords: Cost recovery, Intestinal worms, Social learning, Sustainable development, Peer effects, Cost sharing, User fees, Africa, Sustainability

JEL Codes: I18, I38, O22, Q01, Z13

\footnotetext{
* Acknowledgements: We thank ICS Africa and the Kenya Ministry of Health for their cooperation in all stages of the project, and would especially like to acknowledge the contributions of Alicia Bannon, Elizabeth Beasley, Laban Benaya, Simon Brooker, Pascaline Dupas, Alfred Luoba, Sylvie Moulin, Robert Namunyu, Carol Nekesa, Peter Wafula Nasokho, Polycarp Waswa and the entire PSDP staff, without whom the project would not have been possible. Melissa Gonzalez-Brenes, Tina Green, Jean Lee, Emily Oster, and Avery Ouellette provided excellent research assistance. We thank Andrew Foster, Caroline Hoxby, Guido Imbens, Botond Koszegi, Kaivan Munshi, Mark Rosenzweig, John Strauss, Chris Udry, and numerous seminar participants for helpful suggestions. We are grateful for financial support from the World Bank, NIH Fogarty International Center (R01 TW05612-02), and Berkeley Center for Health Research. All errors are our own.

-- M. Kremer, Department of Economics, Harvard University, Littauer Center, Cambridge, MA 02138, USA, phone: 1 (617) 495-9145, fax 1 (617) 495-7730, email mkremer@fas.harvard.edu.

-- E. Miguel, Department of Economics, University of California, 549 Evans Hall \#3880, Berkeley, CA 94720-3880, USA, phone: 1 (510) 642-7162, fax: 1 (510) 642-6615, email: emiguel@econ.berkeley.edu.
} 


\section{Introduction}

The history of overseas development assistance can be viewed as a series of attempts to identify and address ever more fundamental causes of global poverty. Oxfam, for example, started out in 1942 as the Oxford Committee for Famine Relief, but later shifted to "support for self-help schemes whereby communities improved their own water supplies, farming practices, and health provision”1 . In the 1950's and 1960's, it was widely argued that long-run income levels depended on capital investment, and raising savings through a "big push" (Rosenstein-Rodin 1943) would launch countries into self-sustaining growth or "take-off" (Rostow 1960). Accordingly, the World Bank funded infrastructure, like dams and roads.

However, by the 1980’s international financial institution policymakers decided that capital accumulation and technological progress depended not so much on investment and careful engineering, but rather on a better economic policy environment (Williamson 1990, World Bank 1993a). Development assistance was extended conditionally to encourage countries to adopt economic policies associated with this “Washington consensus” view, characterized by reduced tariffs, appropriate foreign exchange rates and low inflation. By the 1990's, this approach too became widely seen as unsuccessful, and according to a new consensus, the mandated policies would have only limited impact in the absence of fundamental institutional reforms (World Bank 1998).

Part of this new consensus in overseas development assistance thinking involved reforms to national level institutions, but given widespread central government failures in delivering local public goods, another strand emphasized encouraging communities to sustainably provide their own public goods. Whereas orthodox public finance analysis suggests that governments and donors should indefinitely fund activities that generate positive externalities, advocates of sustainability emphasize the importance of local “ownership” of projects, and promote interventions to supply local public goods that only require start-up funding and can then continue without external support. These efforts typically rely on voluntary activities by the community, rather than by granting local governments more coercive fundraising powers.

\footnotetext{
${ }^{1}$ Refer to the Oxfam website for the details (http://www.oxfam.org.uk/about_us/history/history2.htm).
} 
The idea that development projects should aim at financial sustainability through local voluntary action has had tremendous influence in development. Sustainability has other meanings, including an environmental meaning, but here we focus on financial sustainability. In public health, sustainability advocates concentrate on cost-recovery from beneficiaries, community mobilization, and health education rather than simply subsidizing treatments that generate positive externalities. ${ }^{2}$ In the area of water supply, for example, advocates of sustainability argue that, given the history of donor-built projects falling into disrepair, it is essential to organize community water committees that raise funds locally to maintain wells.

Anecdotal evidence suggests that sustainability has often been an illusion, and sometimes a costly one. Morduch (1999) argues that pursuit of sustainability by microfinance organizations has led them to move away from serving the poor, and that it has not in fact yielded organizations that break even financially, but rather just organizations that learn to better hide their continued subsidies. In Niger, a health cost-recovery program led to unexpectedly large drops in health care utilization, and the local health committees set up by the program failed in most of their responsibilities (Meuwissen 2002). In Uganda, funding for immunization, which is consistently rated one of the most cost-effective public health interventions, appears to have fallen following a reform that granted sub-county governments increased responsibility for local health fund raising (Azfar and Livingston 2002). At least in one case, the move away from external donor support for water well maintenance to the training of local committees has allowed water infrastructure to fall into terrible disrepair: in one large water project in the Kenyan area we study, $43 \%$ of bore hole wells were useless ten years after the shift to a "sustainable” approach (Miguel and Gugerty 2004).

While it is certainly true that in some cases communities have developed institutions that lead individuals to contribute to local public goods (Ostrom 1990, Besley and Coates 1995, Miguel and Gugerty 2004), it is less clear that external interventions, such as training sessions or the formation of user

\footnotetext{
${ }^{2}$ Tanner (1998) discusses the concept of sustainable development in regards to health.
} 
committees, reliably lead to sustainable voluntary provision of local public goods. It is difficult for outsiders to understand how institutions, politics and societies function, let alone how to influence them in a way that creates the correct incentives and does not generate unforeseen consequences.

In this paper we provide empirical evidence on the impact of organizing development assistance around the idea of sustainability. We focus on the case of intestinal worms, which infect one in four people worldwide and can be fought in several different ways. One approach emphasizes periodic medical treatment with low-cost drugs. Public provision of deworming medicine can be justified on standard public finance grounds, since an estimated three quarters of the social benefit of treatment comes through reducing disease transmission (Miguel and Kremer 2004).

However, some argue that too much emphasis has been placed on handing out deworming drugs. Since people soon become reinfected, deworming drug treatment must continue twice per year indefinitely. In a Lancet article entitled “Sustainable Subsistomiasis Control - The Way Forward,” Utzinger et al. (2003) argue that rather than focusing narrowly on drugs, a broader approach with greater emphasis on health education would be more sustainable. Other potential ways to make anti-worm programs sustainable include requiring cost-sharing payments from those taking the drugs, encouraging local “ownership” of deworming treatment programs, and designing programs to promote the diffusion of worm prevention information and behaviors through social learning.

This paper uses randomized evaluations to examine various "sustainable” approaches to providing the local public good of worm control without relying on continued external subsidies. First, the introduction of a small fee for the drugs (“cost-sharing”) led to an $80 \%$ reduction in treatment rates relative to free treatment. Take-up dropped sharply when going from a zero price to a positive price, but was not sensitive to the exact price level, suggesting that it may be particularly counter-productive to charge small positive prices for treatment of infectious diseases. Second, a verbal commitment “mobilization” intervention - in which people were asked in advance whether they planned to take deworming drugs, exploiting a finding from social psychology that individuals strive for consistency in their statements and actions - had no impact on treatment rates. Third, intensive school health education 
had no impact on worm prevention behaviors, and thus child health is likely to be worsened to the extent funds are diverted from drug treatment into health education in this setting.

If individuals learn from others about the benefits of deworming drugs and worm prevention behaviors, then a temporary subsidy program or educational effort may have a sustainable long-run impact. A number of recent papers, including Conley and Udry (2000), Foster and Rosenzweig (1995) and Munshi (2002) use non-experimental data to examine social learning in technology diffusion. Analysis of our data using nonexperimental methods suggests that individuals are more likely to take the drugs if they have greater social contact with others who have been exposed to deworming. However, analysis using a more credible experimental approach paints an entirely different picture. The experimental approach relies on the fact that the order in which schools were brought into the program was randomized, generating exogenous variation in the extent to which individuals' social contacts were exposed to deworming. Controlling for the total number of parent social links, each additional social link to an early treatment school reduced the probability their child would take the drugs by 3.1 percentage points, and made it significantly more likely they would say deworming drugs are "not effective”.

The dramatic drop in drug take-up with cost sharing, and the lower take-up among those with more knowledge may both be due to the high proportion of benefits of deworming flowing not to the treated child or her family, but to others in the community through externalities. One interpretation of the social learning patterns is that the NGO implementing the program based its advocacy efforts for deworming by describing its social benefits in community meetings, but as people soon found out that private treatment benefits were smaller, they become less likely to adopt. These results are consistent with a formal model of learning with overoptimistic prior beliefs. Negative social effects on take-up are especially large empirically for families with more schooling, who start with particularly favorable beliefs about the technology, but then revise these beliefs downwards as they acquire more information. This pattern suggests that the widely-noted tendency for the more educated to be early technology adopters could potentially reflect their more optimistic initial beliefs rather than faster learning. The evidence also indicates that the social effects are due to information transmission rather than simple imitation, since we 
find that people with greater exposure to schools where the program was previously introduced are less likely to adopt deworming drugs.

Overall, the empirical results suggest that large continued subsidies may be necessary to sustain high take-up of medicines for diseases characterized by positive treatment externalities like worm infections, a finding especially important for Africa where half the disease burden is associated with infectious and parasitic disease (WHO 1999). More generally, it may be an illusion to think that a small infusion of external assistance will lead to sustainable voluntary provision of local public goods. There may be no alternative to continued subsidies, financed by tax revenue raised from either international donors, national governments, or local governments. ${ }^{3}$

The remainder of the paper is structured as follows. Section 2 describes worm infections, the Kenyan setting, and the deworming project we study. Section 3 presents the cost-sharing results. Sections 4 and 5 describe the verbal commitment and health education results, respectively. Section 6 discusses social learning, and the final section discusses broader implications for overseas development assistance and public finance in less developed countries.

\section{The Primary School Deworming Project (PSDP) in Busia, Kenya}

Over 1.3 billion people worldwide are infected with hookworm, 1.3 billion with roundworm, 900 million with whipworm, and 200 million with schistosomiasis (Bundy 1994). Most have light infections, which are often asymptomatic, but more severe worm infections can lead to iron deficiency anemia, protein energy malnutrition, stunting, wasting, listlessness, and abdominal pain. Heavy schistosomiasis infections can have even more severe consequences. ${ }^{4}$

Helminths do not reproduce within the human host, so high worm burdens are the result of frequent re-infection. The geohelminths (hookworm, roundworm, and whipworm) are transmitted through ingestion of or contact with infected fecal matter, which can occur, for example, if children do not use a

\footnotetext{
${ }^{3}$ Lengeler (1999) reaches similar conclusions in regard to public health programs in poor countries.

${ }^{4}$ Refer to Adams et al. (1994), Corbett et al. (1992), Hotez and Pritchard (1995), and Pollitt (1990).
} 
latrine and instead defecate in the fields near their home or school, areas where they also play. ${ }^{5}$

Schistosomiasis is acquired through contact with infected freshwater. For example, in our Kenyan study area people often walk to nearby Lake Victoria to bathe and fish. Medical treatment for helminth infections creates externality benefits by reducing worm deposition in the community and thus limiting reinfection among other community members (Anderson and May 1991). The geohelminths and schistosomiasis can be treated using the low-cost single-dose oral therapies of albendazole and praziquantel, respectively. The drugs occasionally cause unpleasant and salient, but medically minor, side effects including stomach ache, diarrhea, fever and even vomiting (WHO 1992), but these effects rarely last more than one day. Side effects are more severe for heavier schistosomiasis infections. ${ }^{6}$

In prior work, Miguel and Kremer (2004) found that deworming treatment led to large externality benefits by interfering with disease transmission. Providing worm medicine to school children in Kenya led to large reductions in worm infections and increased school participation among both treated and untreated children in the treatment schools, and among children in neighboring schools. Three quarters of the social benefit from taking medicine was in the form of externalities. Since deworming costs only $\$ 3.50$ per extra year of school participation generated, it is one of the most cost-effective ways to boost participation.

We study the Primary School Deworming Project (PSDP), a school health program carried out by a Dutch non-governmental organization (NGO), ICS Africa, in cooperation with the Kenyan Ministry of Health. The project took place in Busia district, a poor and densely-settled farming region in western Kenya, and the 75 project schools include nearly all rural primary schools in this area, with over 30,000 enrolled pupils between the ages of six and eighteen, over $90 \%$ of whom suffer from intestinal worm infections. In January 1998, the schools were randomly divided into three groups (Group 1, Group 2, and

\footnotetext{
${ }^{5}$ Note that individuals are likely to have at least some knowledge of their infection status, since they can observe certain worms in their stool, and may also see them being expelled from their body after treatment.

${ }^{6}$ The manufacturer of praziquantel (Bayer) states that "Side effects are usually mild and temporary and include abdominal pain, nausea, vomiting, headache, fever, pruritus, drowsiness. Side effects may be more severe in heavy infestations.” (home.intekom.com/pharm/bayer/)
} 
Group 3) of twenty-five schools each: the schools were first divided by administrative sub-unit (zone) and by involvement in other non-governmental assistance programs, and were then listed alphabetically and every third school assigned to a given project group. ${ }^{7}$

The intervention included both health education on worm prevention behaviors and provision of deworming medicine. Due to administrative and financial constraints the program was phased in over several years. Group 1 schools participated in 1998, 1999, 2000 and 2001, and Group 2 schools in 1999, 2000 and 2001, while Group 3 began participating in 2001. This design implies that in 1998, Group 1 schools were treatment schools, while Group 2 and Group 3 schools were the comparison schools; and in 1999 and 2000, Group 1 and Group 2 schools were the treatment schools and Group 3 schools were comparison schools. At each school, the project started out with a community meeting of parents, teachers, and the school committee, which included a discussion of worm infections, the nature of medical deworming treatment, and worm prevention measures. All primary school communities in the baseline sample agreed to participate in the project. Starting in 1999, signed individual parental consent was required for deworming, while in 1998 only “community consent” (a series of meetings at which parents were informed of the program and could opt out) had been required.

Health education efforts focused on worm prevention behaviors, primarily hand washing, wearing shoes, and avoiding infected fresh water. This included classroom lectures and culturally appropriate health education materials developed by the Tanzanian Partnership for Child Development. This health education effort was considerably more intensive than is typical in Kenyan primary schools, and thus the program should be more likely than existing government programs to impact child behavior. Two teachers in each school (one regular teacher and the head teacher) attended a full day training session on worm prevention lessons for schoolchildren as well as the details of the deworming program, and were instructed to impart these lessons to their pupils during normal school hours. These classroom lessons

\footnotetext{
${ }^{7}$ Appendix Table A1 presents a more detailed project timeline.
} 
were supplemented through lectures by an experienced NGO field team (the team leader was a trained Public Health Technician), which visited each school several times per year.

The project provided periodic treatment with deworming drugs at all schools where helminth prevalence was sufficiently high; the drugs were taken by students at the school itself. The World Health Organization has endorsed mass school-based deworming in areas with prevalence over $50 \%$ since mass treatment eliminates the need for costly individual screening (Warren et al. 1993, WHO 1987), and drugs delivered through a large-scale school program may cost as little as US\$0.49 per person per year in East Africa (PCD 1999). Per child annual costs in the program we study were US\$1.49. These higher costs are due to the smaller size of the treated population, which did not allow the program to fully exploit economies of scale in drug purchase and delivery, as well as a greater number of field workers than would be required in a program that did not feature an evaluation component. The project followed the standard practice at the time in mass deworming programs of not treating girls of reproductive age, due to concern about the possibility that albendazole could cause birth defects (WHO 1992, Bundy and Guyatt 1996, Cowden and Hotez 2000). (The WHO recently called for this policy to be changed based on an accumulating record of safe usage by pregnant women - see Savioli, Crompton and Neira 2003).

Our best estimate is that teacher training, teacher lessons in school, the lectures delivered by the mobile NGO field team, and the classroom wall-charts and other educational materials taken together cost at least US\$0.44 per pupil per year in the assisted schools ${ }^{8}$ - which is comparable to the total cost of deworming drug purchase and delivery in a nearby Tanzanian program, at US\$0.49 (PCD 1999). In our case, it is difficult to break out the costs of health education, data collection, and drug delivery since the same field team was responsible for all activities, so these cost estimates should be seen as rough. Nonetheless, they are in line with estimated school health program costs in Jamison and Leslie (1990).

\footnotetext{
${ }^{8}$ This figure is based on an estimate that each health education teacher taught two full hours on worm prevention behaviors in each grade per school year (given an annual teacher salary and benefits of approximately US\$2,000), and that the NGO team also provided two hours of health education per school per year.
} 
The NGO has a policy of including community cost-recovery in all its rural development programs to promote sustainability and confer project ownership on beneficiaries. In the case of deworming, the NGO temporarily waived this policy initially, and then phased it in gradually. The 50 Group 1 and Group 2 schools were stratified by treatment group and geographic location, and then 25 were randomly selected (using a computer random number generator) to pay user fees for medical treatment in 2001, while the remaining 25 continued to receive free medical treatment that year (and all Group 3 schools received free treatment). The fee was set on a per family basis, like most Kenyan school fees. This introduced within-school variation in the per child cost of deworming since households have different numbers of children in primary school, variation that we also use to estimate the effect of price on take-up. Of the 25 Group 1 and Group 2 schools participating in cost-sharing, two-thirds received albendazole at a cost of 30 Kenya shillings per family (US\$0.40 in 2001) and one-third received both albendazole and praziquantel at a cost of 100 shillings (approximately US\$1.30) (whether praziquantel was given depended on the local prevalence of schistosomiasis). Since parents have 2.7 children in school on average, the average cost of deworming per child in cost-sharing schools was slightly more than US\$0.30 - still a heavily subsidized price, about one-fifth the cost of drug purchase and delivery through this program, and $60 \%$ of the cost in the large-scale Tanzania program. ${ }^{9}$

It is worth noting that the study area seems fertile ground for efforts to encourage voluntary community provision of local public goods, like deworming control. Kenya has a long history of community self-help programs, and indeed the national motto of "Haramabee" refers to such programs. The project we examine was conducted at primary schools, one of the most widespread and firmly established institutions in rural Kenya. All primary schools have a school committee composed of parents and other community representatives, and historically these committees have been entrusted with raising funds from the community for most non-salary costs of running the school, including everything from chalk to roof repairs and construction of new classrooms. A number of authors (e.g. Wilson 1992) explore

\footnotetext{
${ }^{9}$ Annual Kenyan per capita income is US\$340 (World Bank 1999), but incomes are thought to be lower in Busia.
} 
the success of Kenyan communities in financing local public goods, and Miguel and Gugerty (2004) find evidence that social sanctions are often employed in rural Kenyan schools to enforce payment of school fees and contributions to school projects.

It is plausible then that the social benefits of deworming drug treatment could be internalized within a small Kenyan community, where formal institutions like school committees and informal social sanctions could together enforce high take-up, even when cost-sharing is introduced. However, Kremer, Moulin, and Namunyu (2002) strike a note of caution, arguing that the local fundraising system in Kenya in fact relies on large-scale subsidies from the central government. Although some school headmasters attempted to rally parents to pay the small deworming fee, through interviews with NGO field staff and deworming program participants, we found no evidence of coordinated community efforts to sanction or pressure those who did not pay.

\section{The Impact of Subsidies on Drug Take-up}

Cost-sharing through user fees has been advocated as necessary for the sustainability of public health services in many less developed countries (World Bank 1993b). Revenues from these fees could be used to improve the quality of health services (i.e., through expanded drug availability), or to fund other government expenditures. User fees could theoretically promote more efficient use of scarce public resources if those in greatest need of health services are most willing to pay for them.

Studies from Africa have found large drops in health care utilization after the introduction of user fees (e.g., McPake 1993, Meuwissen 2002), including in Kenya, where Mwabu et al (1995) find utilization fell by 52\% in 1989. Nonetheless, it remains unclear to what extent user fees have causally affected utilization since cost-sharing is typically introduced during periods of fiscal crisis, making it difficult to separate out the effect of cost-sharing from the effect of crisis. In contrast, our analysis uses random assignment to estimate the effect of cost sharing. ${ }^{10}$

\footnotetext{
${ }^{10}$ Gertler and Molyneaux (1996) find that utilization of medical care is highly sensitive to price in an experimental study in Indonesia, but since the unit of randomization in their analysis is the district, and their intervention affected
} 
Children in 75\% of households in the free treatment schools received deworming drugs in 2001

(Table 1), while the rate was only $18 \%$ in cost-sharing schools (the survey data used in these regressions is described in more detail in Section 6 below). In a regression analysis, the introduction of the small fee dramatically reduced the treatment rate by 62 percentage points (Table 2, regression 1), and the effect is similar for households with different socioeconomic characteristics (regression 2).

Cost-sharing had roughly the same effect on treatment rates regardless of the per child price that the household was required to pay (Table 2, regression 3). ${ }^{11}$ Variation in the deworming price per child was generated by the fact that cost-sharing came in the form of a per family fee, so that parents with more children in the primary school effectively faced a lower price per child. This specification also includes the inverse of the number of household children in treated primary schools, and the total number of children of all ages, as explanatory variables in an attempt to control for the effects of household demographic structure on deworming drug demand. Of course, while these variables control for the main effect of family size on demand, we cannot control for the interaction between family size and price changes given the study's school-level randomization project design. There is a moderate but statistically insignificant decrease in take-up in the albendazole and praziquantel treatment schools (100 shillings per family) relative to the albendazole treatment only schools (with a deworming fee of 30 shillings per family - regression 4), although the interpretation of this result is complicated by the fact that the treatment regime differed across these schools as well.

The drop in take-up in cost-sharing schools is not simply a result of the fact that only the sickest pupils choose to seek treatment in these schools. In fact, contrary to the hypothesis that user fees help

only eleven districts, statistical power is relatively low. In a large-scale experimental study, Manning et al (1987) find in contrast that the price elasticity of demand for medical services in the United States is a modest -0.2 .

${ }^{11}$ This would not be surprising if the bulk of the total deworming cost were the time and money needed to travel to the primary school - which may be several kilometers away - to pay the fee. However, most parents already attend several school meetings per year, and may travel to a market, often located near their child's school, regularly to trade, so we do not believe that travel costs are likely to be prohibitively large in most cases. Most importantly, 2001 treatment rates are high in the Group 3 schools, in which parents received the drugs for free but still had to visit school to sign the consent book, suggesting that the cost of visiting school is not prohibitively high. Ariely and Shampan'er (2004) find sharp increases in demand for goods with a zero price relative to goods with a small positive price in lab experiments. 
ensure that scarce resources are directed to those who need them most, sicker pupils were no more likely to pay for deworming drugs than healthy children: the coefficient estimate on the interaction between 2001 helminth infection status and the cost-sharing indicator is not significant (not shown).

The results suggest that introducing a small positive user fees is a particularly unattractive policy in this context, since it dramatically reduces take-up while raising little revenue, especially since the collection of even low user fees typically requires a considerable administrative cost. Yet this is precisely the approach that many less developed countries, including Kenya, have adopted in the health sector (World Bank 1994, McPake 1993). Although user fees play an important and useful role in some contexts, for medical treatments characterized by large externalities they seem likely to reduce drug treatment far below socially optimal levels.

It is worth bearing in mind the sequencing of the project in interpreting the results. Prior to the program, fewer than 5\% of people reported taking deworming drugs (Miguel and Kremer 2004). While many medicines, such as aspirin and anti-malarials, are cheaply available in nearly all local shops, deworming is available in few shops and then only at high mark-ups, where the markups are high perhaps because the market is quite thin. In fact, none of 64 local shops surveyed in 1999 had either albendazole (or a close substitute, mebendazole) or praziquantel in stock, though a minority of shops carried less effective deworming drugs (levamisole hydrochloride and piperazine). In the parent meetings held to introduce the project, NGO facilitators explained that deworming medicine would be provided for free during an initial introductory period, and that, following standard NGO policy, cost-sharing would be introduced later. Schools then received free treatment for two or three years, after which half the Group 1 and Group 2 schools were assigned to cost-sharing. The rationale behind this sequencing was that people may be more likely to spend money on a new product if they first have the chance to try it out and witness its benefits first-hand.

On the other hand, some could argued that it is essential to introduce cost-sharing from the beginning of a project, the logic being that once people become accustomed to receiving free treatment, they will develop a sense of entitlement and will refuse to pay when positive prices are later introduced. 
Although we are unable to directly test either hypothesis here given the study design, it is worth noting that there was no significant difference in the impact of cost-sharing across Group 1 and 2 schools despite their differing lengths of exposure to free treatment (three versus two years, respectively), exposure that could theoretically have provided a stronger sense of entitlement, or additional information on drug effectiveness, among Group 1 parents. $^{12}$

The huge drop in take-up with cost-sharing, and the extremely low private purchases of deworming drugs suggest most households in the study area place little value on deworming drugs. Even if deworming is socially beneficial, perceived private gains from deworming were smaller than private costs for most households in this setting.

\section{The Impact of Commitment}

Advocates of the sustainability approach often argue that local “ownership” is important for successful public goods projects. At a minimum in this view, projects should only take place if beneficiaries are willing to make an affirmative commitment to them. In the project we study, for instance, treatment only took place only after a community collectively decided to participate during a village meeting.

The notion of ownership also relates to the claim in social psychology that asking individuals if they plan to take an action can make it more likely that they carry through with it. A number of studies suggest that individuals can be motivated to take socially beneficial but individually costly actions by being asked whether they intend to perform them. Most people answer that they do, and then feel motivated to follow through with their commitment. For example, Greenwald et al. (1987) asked U.S. university students whether they would vote in an upcoming election. All voters in the sample were reminded that Election Day was coming up, and a random half of these voters were also asked if they

\footnotetext{
${ }^{12}$ Take-up of the deworming drugs fell somewhat in Group 1 schools between 1998 and 1999 (from 78 to $73 \%$ among those still enrolled in school, see Miguel and Kremer 2004). This may be due to the change from community consent to individual consent between 1998 and 1999, since in the community consent system the default was deworming treatment, while in the individual consent system the default was no treatment. However, it is also possible that people learned that the private benefits of treatment were lower than they had anticipated. Of course, there may also be other reasons for year-to-year variation in take-up - for instance, El Niño flooding took place in early 1998 and may have affected take-up both in 1998 and 1999 - further complicating interpretation of the pattern.
} 
intended to vote; all answered that they did. Using county election records, Greenwald et al. find that 81\% of the voters who made the verbal commitment actually did vote in the election, compared to only $57 \%$ of those just reminded about the election. To take another example, Cioffi and Garner (1998) find large impacts of such commitments on blood donation in a U.S. university campus.

In an application of this technique, a random subsample of pupils in PSDP schools were asked whether they would take deworming drugs in the upcoming treatment round, in an attempt to boost drug take-up without providing additional external subsidies. During 2001 Pupil Questionnaire administration, all children were told that worms and schistosomiasis can lead to poor health and make children feel tired, but they were also told that drugs can eliminate the worms. All were given the date of the upcoming ICS treatment intervention. A random subsample of pupils were then asked whether they were planning to come to school on the treatment day and whether the PSDP workers should bring pills for them on that day; 98\% of children answered "Yes" to both questions. All pupils interviewed - including both those offered the opportunity for verbal commitment and those not offered this opportunity - were provided the same information on the effects of deworming and the upcoming date of medical treatment. (All were of course also informed that participation in data collection and treatment was completely voluntary.)

The verbal commitment intervention failed, reducing drug take-up by one percentage point in 2001, although this effect is not statistically significant (Table 3, regression 1). This result is robust to controls for pupil age and gender (regression 2), and the impact of the intervention did not vary significantly with age or gender (regression 3). The effect is somewhat more negative for pupils in costsharing schools and those with moderate-to-heavy worm infections, although in neither case are the estimates on these interactions significantly different than zero (results not shown).

These results suggest that mobilization or marketing techniques found to induce people to take socially beneficial actions in a particular U.S. population may fail in other contexts. ${ }^{13}$ The precise reason

\footnotetext{
${ }^{13}$ In recent work, Smith et al. (2003) also fail to replicate the Greenwald et al. (1987) finding among a broader population of U.S. voters, not just college students, indicating that interventions that work in one U.S. population can even fail in another U.S. age group.
} 
why is unclear. One hypothesis is that students interpreted the fact that the interviewer felt it necessary to ask them to participate in the project as a negative signal about deworming. However, if the verbal commitment intervention was perceived as providing negative information, this effect should be smaller for pupils who knew more about deworming already; but in fact, we find that there is no significant difference in the effect of the commitment intervention on pupils across the three program treatment groups, with their varying exposure to deworming (results not shown). The bottom line is that a cheap mobilization technique did not boost drug take-up, but take-up was highly sensitive to drug subsidies.

\section{The Impact of Health Education}

The attractiveness of health education versus continued external subsidies depends on three factors: (i) the relative cost effectiveness of health education and subsidies on immediate recipient behaviors, (ii) the rate at which health education knowledge depreciates and (iii) the rate at which the new knowledge and practices spread to others through social learning.

In the deworming case we study, the health education intervention appears less attractive than

external subsidies. ${ }^{14}$ First, although program expenditures on health education were the same order of magnitude as expenditures on drugs, this section argues that there was no detectable effect on the immediate beneficiaries of health education in the adoption of worm prevention practices. Although we cannot directly measure the depreciation of knowledge, other researchers find that depreciation of health education knowledge and practices is rapid even in settings where direct short-run program impacts were positive (see Haggerty et al 1994, Aziz et al 1990, Hoque et al 1996). Finally, in section 6 below we find no evidence that worm infection knowledge: individuals who have (randomly) more social links to early treatment schools are themselves no more able to name worm infection symptoms than other individuals.

Recall that the health education efforts undertaken through the program stressed hand washing, wearing shoes, and avoiding fresh water. There were no significant differences across treatment and comparison school pupils in early 1999 (one year into the program) on these three worm prevention 
behaviors: pupil cleanliness (of the hands and uniform) observed by enumerators ${ }^{15}$, the proportion of pupils observed wearing shoes, or self-reported exposure to fresh water (Table 4, Panel A). The results do not vary substantially by pupil age, gender, or grade (results not shown). As we found with cost-sharing for deworming drugs, individuals appear unwilling to take a costly private action - here, buying shoes for their children or learning new hygiene practices - that help to combat worms in their local community.

One alternative explanation is that treatment school children neglected to adopt worm prevention practices precisely because they were also taking deworming drugs, and thus felt protected from infection. This does not seem to explain the lack of health education impacts, however, since there was no evidence of behavioral change even among older girls who were excluded from medical treatment (due to its potential embryotoxicity, Table 4, Panel B). It also seems implausible that the older girls in treatment schools neglected to adopt better worm prevention practices because they realized that they were benefiting from treatment spillovers. The lack of even basic knowledge regarding worm infection symptoms and transmission among most residents in this area makes this possibility seem remote: the average resident in this area is able to name just 1.8 of ten common worm infection symptoms (as we discuss below), and fewer still can accurately describe transmission mechanisms. Moreover, there is no evidence that other children benefiting from treatment spillovers changed their prevention behavior: children attending comparison (Group 2) primary schools located near deworming treatment schools in early 1999 showed large reductions in worm infection levels (Miguel and Kremer 2004) but did not receive health education, and there was no significant change in their worm prevention behaviors (Table 4, Panel C) - although these effects are imprecisely estimated statistically.

\section{Networks, Social Learning and Technology Adoption}

\footnotetext{
14 This result is consistent with Pant et al (1996), who show that hygiene education for mothers is considerably less cost-effective than Vitamin A capsules in reducing infant morbidity and mortality in Nepal.

15 This also holds controlling for initial 1998 cleanliness, or using difference-in-differences (not shown).
} 


\subsection{A Model of Learning about a Health Technology}

Temporary programs to promote a new health technology or practice could potentially lead to sustainable public health improvements if people learn about its effectiveness and spread this information to others. Below we examine the spread of deworming drug adoption and worm prevention knowledge using a simple Bayesian framework in which individuals can potentially learn about the private benefits of a new technology through their social networks.

Consider an individual $i$ in school $j$ deciding whether to adopt a new technology (or health practice), where an indicator variable for take-up is represented by $T_{i j} \in\{0,1\}$. We represent the individual's expected net private benefits from adoption by $\phi=E\left[U\left(T_{i j}=1\right)-U\left(T_{i j}=0\right)\right]$, where $U$ is individual utility, benefits conditional on the treatment choices of other individuals.

At the moment the new technology is introduced, the individual has a prior belief about the expected net private benefits, denoted $\phi_{0}$, which may be greater or less than the actual expected benefit $\phi$. Prior beliefs about the impact of deworming may have been variable across individuals in our case since most had little or no prior experience with mass deworming treatment. $\phi_{0}$ could be less than $\phi$ due to traditional beliefs about worms that emphasize their health benefits rather than their costs (Geissler 1998). On the other hand, people could also have had overly optimistic estimates about private benefits. Although the scripts used during the community meetings held to publicize the program did explain that people could become reinfected after taking deworming drugs, the NGO field officers who gave the talks saw their jobs as promoting deworming, and their enthusiasm may have reflected the social rather than private benefits of the drugs. If people estimated the private benefit of treatment by simply comparing the health status of infected and uninfected people, they could similarly overestimate the effect of treatment, since treatment provides only short-run protection. Moreover, if people estimated their expected private benefits by comparing individuals in treatment versus comparison schools, to the extent that there are positive within-school treatment externalities, they would incorrectly assign some of the externality effects to private benefits - again making prior beliefs about net private treatment benefits overoptimistic. 
Here we assume prior beliefs are based on $n$ independent signals about treatment benefits, and that individuals combine this prior information with additional information received from their social links in the early treatment schools. Individuals have $N_{i j}^{E}$ early treatment links, and each such link yields one additional signal about net private benefits, a noisy signal based on the link’s own experiences as well as the link's observations of others. Individuals then compute the sample average of private signals from their prior beliefs and their social links, and the posterior belief on expected treatment benefits for an individual with $N_{i j}^{E}$ early treatment links becomes:

$$
E\left[U\left(T_{i j}=1\right)-U\left(T_{i j}=0\right) \mid N_{i j}^{E}\right]=\alpha\left(N_{i j}^{E}\right) \cdot \phi_{0}+\left(1-\alpha\left(N_{i j}^{E}\right)\right) \cdot \phi
$$

where $\alpha\left(N_{i j}^{E}\right)=\frac{n}{n+N_{i j}^{E}}$, which goes to zero as individuals accumulate information through their social network, and as posterior beliefs approach the true expected benefit. ${ }^{16}$ This framework is the reducedform of a model in which each social link uses a simple updating rule, comparing outcomes across the treated and untreated children they observe in order to estimate the net private treatment benefit- the variable of immediate interest, and the signal they pass on. Implications are likely to be similar to a model in which people learn about the full underlying epidemiological model. ${ }^{17}$

The solution is intuitive: when the prior belief is greater than the actual expected benefit $\left(\phi_{0}>\phi\right)$, individuals with more early treatment social links have falling posterior beliefs about expected benefits on average, and thus the likelihood of adoption declines in the number of early treatment links. From equation 1 , the decline in the expected benefit of treatment with respect to early links will be convex as in

\footnotetext{
${ }^{16}$ For simplicity, we focus on the social dimension of learning and do not consider the case where individuals experiment today to gain information about the technology for future rounds.

${ }^{17}$ Although individuals would be better able to react to changes in public policy or to the disease environment in a theoretical framework where they learn about the underlying epidemiology, we do not think such a model is realistic in this context, at least in the short run. The epidemiological model is complicated and few individuals in this area have even basic knowledge about worm infections; as discussed below, residents can name just 1.8 of 10 common worm infection symptoms on average, and fewer still can accurately describe infection transmission.
} 
Figure 1, as the posterior asymptotically approaches the true expected benefit. Similarly, when the prior is less than the true expected benefit, the posterior asymptotically approaches the true benefit from below.

The prior belief can be a function of an individual characteristic $X_{i j}$ such that $\phi_{0, i j}=\phi_{0}\left(X_{i j}\right)$, and we assume $\phi_{0}{ }^{\prime}>0$ without loss of generality. In the context of rural Kenya, formal schooling is considered an important predictor of favorable views about new health technologies (Akwara 1996, Kohler et al. 2001). ${ }^{18}$ This could reflect either the causal impact of education, or simply the fact that individuals who are more open to "modern" or "western" things are likely to obtain more education. When $\phi_{0}\left(X_{i j}\right)>\phi$ for all $X_{i j}$, individuals with more education generally have higher adoption, but additional early links lead to sharper drops in adoption. Formally,

$$
\frac{\partial^{2} E\left[U\left(T_{i j}=1\right)-U\left(T_{i j}=0\right) \mid N_{i j}^{E}\right]}{\partial N_{i j}^{E} \partial X_{i j}}=-\phi_{0}^{\prime}\left(X_{i j}\right) \cdot \frac{n}{\left(n+N_{i j}^{E}\right)^{2}}<0
$$

Because this cross-partial term is always negative, as the prior belief becomes more optimistic additional information will either cause a sharper drop (if $\phi_{0}\left(X_{i j}\right)>\phi$ for all $\left.X_{i j}\right)$ or a slower increase (if $\left.\phi_{0}\left(X_{i j}\right)<\phi\right)$ in the posterior belief about net private benefits.

Treatment benefits may also be a function of an individual health characteristic $W_{i j}=W\left(N_{i j}^{E}\right)$, such that $\phi_{i j}=\phi\left(W\left(N_{i j}^{E}\right)\right)$, where health is allowed to be a function of early social links. $W_{i j}$ should be thought of as the individual worm infection level, where people with higher infection levels typically have greater treatment benefits, so $\phi^{\prime}>0$. Infection levels are also a function of social links due to epidemiological externalities. Children whose families have close social interactions with households in early treatment schools may experience somewhat lower helminth reinfection rates and thus reductions in infection intensity, in which case $W^{\prime}<0$. The impact of early treatment links on the likelihood of adoption is presented in equation 3 (where we make the algebraically convenient assumptions that $\phi_{0}{ }^{\prime}=\phi^{\prime}$ and $\phi_{0}{ }^{\prime \prime}=\phi^{\prime \prime}=0$ at all infection levels, along the lines of a Taylor approximation): 


$$
\begin{aligned}
\left.\frac{\partial E\left[U\left(T_{i j}=1, W\left(N_{i j}^{E}\right)\right)-\right.}{\partial N_{i j}^{E}}\left(T_{i j}=0, W\left(N_{i j}^{E}\right)\right) \mid N_{i j}^{E}\right] \\
\quad=\left\{\left[\phi\left(W\left(N_{i j}^{E}\right)\right)-\phi_{0}\left(W\left(N_{i j}^{E}\right)\right)\right] \cdot \frac{n}{\left(n+N_{i j}^{E}\right)^{2}}\right\}+\left\{W^{\prime}\left(N_{i j}^{E}\right) \cdot \phi^{\prime}\right\}
\end{aligned}
$$

The first right-hand side term is the information social effect and is negative when prior beliefs are overly optimistic, as above. The second term is the infection social effect. This should also be negative because having more early treatment links can lead to lower infection levels (due to epidemiological externalities), which in turn reduces treatment benefits. As we discuss below, the infection social effect is small empirically, largely because child infection status only weakly affects deworming drug take-up.

The modeling of infection externalities deserves further elaboration. In the short run, treatment rids the individual of worms, but in the medium run the local disease environment, not the current treatment choice, determines whether or not an individual is reinfected. The effect of other people's treatment choices on the magnitude of private treatment benefits is unclear a priori. As a benchmark case, if helminth reinfection rates are independent of the current worm load, and if the health burden of infection is linear in worm load, the private health benefits of treatment are independent of others' treatment choices. If, instead, the health costs of infection are convex (concave) in worm load, deworming treatment benefits will be greater (smaller) in an environment that is expected to have high exposure to worms in the future. Thus the net private benefits of treatment will be lower (higher) if others are treated. In a previous study (Miguel and Kremer 2004), we estimated average deworming treatment spillovers and found that they are roughly linear in local take-up rates, but due to data limitations we had little power to detect higher order nonlinear terms. For simplicity, we thus assume the benchmark linear case holds.

\section{$\underline{6.2 \text { Estimating Social Effects }}$}

\footnotetext{
${ }^{18}$ We thus depart from the standard assumption of common priors. For theoretical examinations of how different beliefs on political and health issues can persist, refer to Piketty (1995) and Das (2000), respectively.
} 
Several issues arise in interpreting the existing empirical social effects literature. First, establishing the existence of social effects in nonexperimental studies is complicated by the possibility of omitted variable bias. People with similar characteristics, tastes, and beliefs may associate in the same social networks (Manski 1993), and correlations among outcomes within networks may reflect these commonalities (or common shocks) rather than social learning. Although the nonexperimental literature attempts to address the issue using panel datasets containing rich information on individual and local characteristics (most notably Conley and Udry 2000), ruling out omitted variable bias is often difficult. This paper, as well as Duflo and Saez (2003), address the issue by randomizing exposure to a new technology.

Second, showing that technology adoption is influenced by contact with earlier adopters is not sufficient to distinguish learning and imitation. For instance, people may be more likely to adopt contraceptives if they know other adopters, and although this relation may be causal it could be as much due to the breakdown of social norms against contraceptives as to learning (as in Munshi and Myaux 2002). We are able to address this issue by collecting information directly on individuals' knowledge and beliefs, and by examining a technology that did not spread, one that yielded private benefits that most people apparently did not value highly.

Finally, in many contexts researchers are forced to impose a preexisting definition of which peer group people learn from. For example, some researchers have compared people who are geographically close to each other (Burke et al. 2003, Foster and Rosenzweig 1995) or work in the same department within an organization (Duflo and Saez 2003). However, understanding the networks through which information flows is important both theoretically and for public policy. Missing these channels could also lead to the underestimation of actual flows. To understand the channels, we collected survey data on social networks in which respondents could designate their own reference groups. ${ }^{19}$

\subsection{Data, Measurement, and Estimation}

${ }^{19}$ Conley and Udry (2000) use a related survey approach. 
The empirical work employs a new dataset that allows us to estimate the impact of parent social links. We use these data to test whether households with more social links to early treatment schools were more likely to take deworming drugs in 2001, conditional on their total number of social links to all project schools. The experimental design created exogenous random variation in the proportion of individuals whose children attend “early treatment” schools (Groups 1 and 2) versus “late treatment” schools (Group 3), and this is the variation we exploit.

The PSDP Parent Questionnaire was administered by experienced enumerators under the supervision of NGO field managers in 2001. ${ }^{20}$ Parent Questionnaires were collected during household visits among a representative subsample of parents with children currently enrolled in Group 2 and Group 3 schools. A subsample of children (typically aged 10 to 17 years) present in school on the survey day were administered the Pupil Questionnaire. Survey refusal rates were low, as is typical for this region. Parent Questionnaire respondents were asked for information on their closest social links: the five friends they speak with most frequently, the five relatives they speak with most frequently, additional social contacts whose children attend local primary schools, and individuals with whom they speak specifically about child health issues. These individuals are collectively referred to as the respondent's set of “social links.” The survey also collected information on the deworming treatment status of social links' children and the effects of treatment on their health; how frequently the respondent speaks with each social link; which primary schools links' children attend; the global positioning system (GPS) location of the respondent's home; and the respondent's knowledge of worm infections and attitudes toward deworming. The Parent Questionnaire was administered in two rounds in 2001, with households randomly allocated between the rounds. The Round 2 survey collected more detailed information on the impact of deworming on links' children. ${ }^{21}$ Two different samples are used in the analysis. Sample 1

\footnotetext{
${ }^{20}$ The dataset and documentation are available from the authors upon request.

${ }^{21}$ A second survey, the 2001 Pupil Questionnaire, collected similar information on social networks and attitudes toward deworming from schoolchildren. Not all children were administered the 2001 Pupil Questionnaire. Some were excluded because of limited financial resources for the research (which forced us to interview a representative subsample of children present in school on the survey day rather than all children), and others because of absence
} 
contains the 1,678 parents surveyed in Rounds 1 or 2 with complete child treatment and parent social network data. ${ }^{22}$ Sample 2 contains the 886 parents surveyed in Round 2 with information on the social links’ own deworming experiences.

On average, parent respondents have 10.2 social links with children in primary school, of whom 4.4 attend the respondent's child's own school, 2.8 attend other project schools (Groups 1, 2, or 3), and 1.9 attend nearby "early treatment schools” (Groups 1 and 2-Table 5, panel A). There is considerable variation in the number of early treatment links: the standard deviation is 2.0, and approximately one third of respondents have no social links to Group 1 or 2 schools, one third have one or two links, and one third have three or more links.

The analysis with parent social network data is conducted at the household level using probit estimation, and the outcome measure takes on a value of one if any child in the household was treated with deworming drugs in 2001, and zero otherwise (although results are similar if the analysis is conducted using the child as the unit of observation, results not shown). ${ }^{23} T_{i j}$ is the main dependent variable, the 2001 treatment indicator described above, where $i$ is a household in school $j$. The idiosyncratic deworming benefit term, $\varepsilon_{i j}$, captures unobserved variation in parent beliefs about deworming benefits or the costs of obtaining treatment (for instance, whether the pupil was sick on the treatment day, which increases the cost of walking to school). The individual treatment decision becomes $T_{i j}=1\left(\lambda N_{i j}^{E}+X_{i j}{ }^{\prime} \beta+\varepsilon_{i j}>0\right)$, where $N_{i j}^{E}$ is the number of parent social links to early treatment schools (not including the respondent's own school), and early treatment schools in 2001 are defined as the Group 1 and 2 schools. We also examine the proportion of links to early treatment schools as a robustness check.

from school on that day. We do not focus on the child data below, although we plan to explore related issues of learning among children in future research.

${ }^{22}$ A reasonably modest $13 \%$ of surveyed households were dropped due to either missing parent network information, child treatment information, household characteristics, or difficulty matching observations across the 2001 surveys and earlier PSDP datasets.

${ }^{23}$ Treatment choices across children within a family are highly correlated, as expected, and hence the focus is on the household as the unit of observation. 
Among the explanatory variables, $X_{i j}$, we include total links to all program schools other than the respondent's own school, as well as the number of links to nonprogram schools (represented by the vector $N_{i j}$ ). Given the experimental design of the original deworming program, the number of social links to early treatment schools is randomly assigned conditional on total links to other program schools. The interpretation of the coefficient estimate on another term, the total number of links, is complicated by the possibility that more sociable individuals (i.e., those able to name more social links) differ from less sociable people in certain unobserved dimensions. However, given the experimental design, this does not affect the estimated impact of early treatment links, since the number of early treatment links is orthogonal to the error term conditional on the total number of links.

The cost-sharing indicator variable, $C_{j}$, takes on a value of one for schools participating in the cost-sharing project. $Z_{i j}$ is a vector of additional household socioeconomic characteristics (parents' education and asset ownership), demographic characteristics (respondent fertility), and other controls (respondent membership in community groups, and a Group 2 indicator) that may affect real or perceived deworming benefits and costs. Idiosyncratic disturbance terms are allowed to be correlated within each school as a result of common influences, such as headmaster efforts in promoting the program. Equation 4 presents the main probit specification:

$$
\operatorname{Pr}\left(T_{i j}=1\right)=\Phi\left\{\lambda_{1} N_{i j}^{E}+N_{i j}{ }^{\prime} \lambda_{2}+\gamma_{j}+Z_{i j}{ }^{\prime} \theta+\varepsilon_{i j}\right\}
$$

We also include interaction terms between household characteristics and social links in some specifications to estimate heterogeneous treatment effects, for example, as a function of respondent education.

To validate the experimental identification strategy, we confirm that the randomization succeeded in creating balanced early treatment and late treatment groups: the number of social links to early treatment schools, as well as the Group 2 indicator variable and the cost-sharing indicator, are not significantly associated with most observable household characteristics (Table 6), including parent years of education, community group membership (e.g., women's or farming groups), the total number of 
children in the household, or the distance from home to the primary school, or with household ethnic group or religious affiliation (results not shown). The number of early links is, however, positively and significantly associated with iron roof ownership in one specification (Table 6, regression 4).

We do not attempt to estimate learning through self-experimentation with deworming drugs below. In the absence of other factors affecting take-up patterns across treatment rounds, it might be possible to identify this effect, but changing parent consent requirements, and changes in child infection status and the local disease environment after treatment, all likely affected take-up through time. We discuss additional econometric issues in section 6.6.

\subsection{Nonexperimental Social Effect Estimates}

We begin by presenting nonexperimental social effect estimates. In a specification similar to many existing nonexperimental studies, we examine the take-up rate of children in a predefined local social unit—here the primary school—as the key explanatory variable. We find that the local school treatment rate (excluding the respondent) is strongly correlated positively with take-up as expected, with coefficient estimate 0.84 (standard error 0.11 - Table 7 , regression 1). Take-up among children who are members of the respondent's own ethnic group in their school is more influential than take-up in other ethnic groups (p-value=0.09, regression not shown), a finding similar to Munshi and Myaux (2002), although in our case we argue that this pattern is due to omitted variable bias rather than to actual social learning as they claim. Similarly, there is a positive, though statistically insignificant relationship (estimate 0.015, standard error 0.011, regression 2) between the number of treated links named in the survey (among those attending the respondent's school) and take-up, in a specification similar to several recent studies (Bandiera and Rasul 2002, Kohler et al. 2001).

Social links' experiences with deworming may also affect the information individuals receive. In particular, we test whether take-up is higher when links had "good" experiences with the technology, as in 
Conley and Udry (2000). ${ }^{24}$ This nonexperimental analysis suffers from reporting bias if individuals who themselves hold more positive views toward treatment are more likely to report their links had good effects, even if the links’ experiences were not particularly good. There is suggestive evidence that having more links whose children had "good effects" is associated with somewhat higher take-up, while those with more links who had "side effects" are less likely to be treated (Table 7, regression 3) — the p-value on the hypothesis that the two estimates are equal is 0.22 -but this is ultimately inconclusive. ${ }^{25}$

\subsection{Experimental Social Effect Estimates}

Experimental social effect estimates are markedly different from the nonexperimental estimates, suggesting that omitted variable bias in the nonexperimental estimates is large and positive in this context. Each additional parent social link to an early treatment school is associated with 3.1 percentage points lower likelihood that the respondent's children received medical treatment in 2001, and this effect is significantly different from zero at over 95\% confidence (Table 8, regression 1 presents marginal probit estimates evaluated at mean values). This suggests that the respondent's small, self-defined social network has a major impact on treatment choices: having two additional early treatment links (roughly a one standard deviation increase) reduces take-up by 6 percentage points. Moreover, this result cannot simply be due to imitation, since social effects are negative.

Figure 2 graphically presents nonparametric social effect estimates (using Fan local regression conditional on the explanatory variables in Table 8, regression 1) and indicates that the relation between

\footnotetext{
${ }^{24}$ One drawback of our dataset is that we only have information on links' deworming choices provided by the respondent herself (unlike Conley and Udry 2000, we did not collect social links's full names for privacy reasons, and are thus unable to match the social links to the main database).

${ }^{25}$ The deworming experiences and choices of people in social links' communities may affect respondent take-up (as in Munshi 2000). For each early treatment school, we computed the average difference in 1999 school participation between treated and untreated pupils and use this to classify schools into "large treated minus untreated difference" schools (those above the median difference) versus small difference schools. The treated minus untreated difference captures the average observed private benefit to deworming in that school. However, the effect of links to early treatment schools where the difference in school participation between treated and untreated pupils was large is not significantly different than the effect of links where the difference was small. Similarly, links to early treatment schools with low take-up do have a somewhat more negative effect on respondent treatment rates than links to schools with high take-up, but the difference is not significant (regression not shown). However, limited statistical power means these results should be interpreted cautiously.
} 
the number of early treatment links and take-up is negative and somewhat convex, consistent with our learning model. A quadratic term in parent social links to early treatment schools is also statistically significantly different from zero at 95\% confidence in some specifications (appendix Table A2). However, this quadratic term is not significant for interactions with household characteristics (results not shown), and we principally focus on the linear measure of links for simplicity in what follows.

None of the demographic or socioeconomic controls is significantly associated with 2001 take-up except for distance from home to school, which is negatively related to take-up. This finding makes sense since geographically distant households face higher costs for parents to walk to school to provide written consent, and for children to attend school. Years of education is positively but not statistically significantly associated with higher take-up (point estimate 0.003 , standard error 0.003 , Table 8 , regression 1).

Social effects are much more negative for Group 3 schools (point estimate -0.041 , Table 8 , regression 2) than for Group 2 schools (point estimate -0.023, the sum of the direct effect of early treatment links and its interaction with the Group 2 indicator), although the difference is not statistically significant. This pattern of coefficient estimates is consistent with the theoretical model: Group 2 parents have by 2001 already observed the impact of deworming treatment in their own household and community and should therefore be less influenced than Group 3 parents by early links (i.e., in Equation 1, $n$ is larger for Group 2 parents than Group 3 parents). Nonetheless, the persistent influence of early links on Group 2 households after two years of treatment is noteworthy. One potential non-Bayesian explanation is that initial pieces of information about a new technology carry disproportionate weight in subsequent decision making (as in Rabin and Schrag 1999). A finding that casts some doubt on the "first impressions matter” explanation, however, is the fact that links to Group 1 schools (phased in during 1998) have nearly identical impacts as links to Group 2 schools (phased in during 1999, regression not shown). Note that the persistent effects of early treatment links on take-up might be reconciled with Bayesian learning, though, if individuals believed there was a school-year specific random component to drug treatment effects, leading them to place extra weight on outcomes in other schools. 
The results are robust to including the proportion of links with children in early treatment schools, rather than the number of such links (Table 8, regression 3), and to controlling for the total number of parent social links nonparametrically using a set of indicator variables (results not shown). The effect of early links is nearly identical for cost-sharing and other schools (not shown). ${ }^{26}$

Several pieces of evidence suggest that learning takes place not only among individuals with strong social ties but also among those with relatively weak ties, along the lines of Granovetter (1973). When the framework is extended to include different types of parent social links - "close” friends, defined as those with whom the respondent speaks at least twice a week, versus relatively “distant” friends - each additional close link to an early treatment school is associated with 0.030 lower probability of deworming treatment in 2001 and the estimated effect of distant links is similar, although not statistically significant (Table 8 , regression 4 , estimate -0.033 , standard error 0.033 ). ${ }^{27}$ We are similarly unable to reject the hypotheses that the social effect on take-up is the same for links to relatives versus friends, or for members of the respondent's own ethnic group versus other ethnic groups, conditional on being named a social link by the respondent (results not shown). One explanation for the ethnic result may be that more than $90 \%$ of individuals in this area belong to closely related ethnic Luhya groups and thus have strong linguistic and cultural ties even across most group boundaries. ${ }^{28}$

\footnotetext{
${ }^{26}$ The results are also robust to a specification without socioeconomic controls (appendix Table A2, regression 1), and to the inclusion of additional ethnic and religious controls, and indicators for whether the respondent is a member of the dominant local ethnic and religious group (regression 2); none of the six ethnic group indicator variables is significantly related to take-up. The results are similar when the local density of early treatment school pupils (located within $3 \mathrm{~km}$ of the respondent's school), and the density of all local primary school pupils, are included as controls (regression 4). However, the point estimate on early links falls by about one third and becomes statistically insignificant, possibly because the local density measures are in part also picking up the effect of interactions with individuals not included in the social links roster. Still, an F-test indicates that the early treatment social links and local density of early treatment pupils terms are jointly significant at $99 \%$ confidence.

${ }^{27}$ Using another definition of link strength yields similar results. While most links were provided in response to questions about the individuals with whom the respondent speaks most frequently, others were provided in response to prompts about contacts in particular local schools. There is not a statistically significant difference in the effects of "unprompted" and "prompted" links (in fact, prompted links are somewhat more influential—not shown).

${ }^{28}$ The largest Luhya subtribes in this area include Samias (64\% of children), Nyalas (27\%), Khayos (1\%), and Marachis (1\%). These are considered separate ethnic groups in the above analysis, although whether subtribes constitute separate "ethnic groups" is debatable. The two substantial non-Luhya groups in the sample are Luos (4\%) and Tesos (1\%). On average, $67 \%$ of named social links outside of the respondent's own school belong to the same ethnic group, a figure similar to the average proportion of the largest group in a primary school (68\%).
} 
Social effects are more strongly negative for respondents with more education (Table 8, regression 5), which is consistent with the prediction that individuals with the most optimistic priors experience the largest drops in take-up when they receive additional information. Other studies—most notably Foster and Rosenzweig (1995)—find that educated individuals learn rapidly about new technologies. In other cases, this has led more educated individuals to be early adopters, unlike our case, where they are the first to learn not to adopt. Note that the overall impact of an additional year of schooling on deworming take-up remains positive, though not statistically significant (in regression 5) when all the education interaction terms, including the terms interacting education with total social links, are taken into consideration (coefficient estimate not shown).

In the theoretical framework presented above, additional social links have a larger impact on more educated individuals because of their overly optimistic prior beliefs about the drugs, rather than any greater receptiveness to new information. Although we cannot decisively distinguish these explanations empirically, the relation between respondents' education and their stated belief that deworming drugs are "very effective” does provide some further evidence supporting the overoptimism model. Among Group 3 parents interviewed in Round 1, before deworming treatment was phased into their schools, there is a particularly strong link between education and positive views: individuals who had completed primary school were 17 percentage points more likely to believe the drugs are "very effective.” However, this falls by about half to 9 percentage points for more educated Group 3 parents interviewed in Round 2 (recall parents were randomly allocated between survey rounds), several months after deworming had been introduced into their schools, and is similar for educated Group 2 parents in 2001, at 10 percentage points, two years after these schools had begun receiving treatment. Among Group 3 parents who had completed primary school, the perceived effectiveness of deworming also fell dramatically from $59 \%$ to $45 \%$ from Round 1 to Round 2, and fell by a smaller amount among less educated parents. To summarize, by Round 2 of the survey views toward the drugs had partially converged across parents with different educational levels and the drugs were increasingly viewed as ineffective among Group 3 parents, and both of these patterns are predicted by the model in section 6.1. 


\subsection{Further Econometric Identification Issues}

Even though the randomization was largely successful in creating comparable groups, social links to early treatment schools might also affect adoption through infection social effects. However, we argue that infection effects cannot explain even a small fraction of the overall social effect of $-3.1 \%$ (Table 8 , regression 1), since any plausible estimate of the effect of social contacts in early treatment schools on infection status, times the effect of infection on take-up, is much smaller.

First, having additional social links to early treatment schools is associated with lower rates of moderate-heavy helminth infection, as expected (Table 6, regression 6), but the effect is relatively small and not statistically significant (coefficient estimate $-1.2 \%$, relative to a mean moderate-heavy infection rate of 27\%). This relatively weak relation between early treatment social links and child infection status is not inconsistent with the strong infection externality findings in Miguel and Kremer (2004). Worm infections are not transmitted directly person to person, but rather through contaminated soil and water, and a child's named social links constitute only a small fraction of all people who defecate in fields near the child's home, school, market, and church, or who bathe at the same points on Lake Victoria.

In terms of the second step-from infection status to take-up—prior infection status is not significantly associated with drug treatment for either Group 1 in 1998 or Group 2 in 1999 (Miguel and Kremer 2004), or for Groups 2 and 3 in 2001 (results not shown) and the point estimates suggest that moderate-to-heavy worm infection is weakly negatively related to treatment rates. ${ }^{29}$ Of course, the crosssectional correlation between infection and treatment cannot be interpreted as causal due to omitted variable bias; children from unobservably low socioeconomic status households may have both high infection rates and low take-up, for example. However, the treated and untreated look remarkably similar along many observable baseline socioeconomic and health characteristics (Miguel and Kremer 2004), and

\footnotetext{
${ }^{29}$ The 2001 worm infection results are for a subsample of only 575 children who were randomly sampled for stool collection, and were present in school on the day of the parasitological survey. Due to the relatively small sample size, we do not focus on the parasitological data in the main empirical analysis.
} 
the relationship is similar using school-level average infection rates rather than individual data (not shown), weakening the case for strong selection into deworming treatment.

Further evidence on the effect of infection status on drug take-up is provided by the 1999 crossschool infection externality estimates, identified using exogenous program variation in the local density of early treatment schools. Although we find large average reductions in moderate-heavy worm infection rates as a result of cross-school externalities (an average reduction in infection of 0.23 , see Miguel and Kremer 2004), proximity to early treatment schools leads to an average reduction in drug take-up of only 0.02 — which has the expected sign but is near zero (regression not shown). Using this estimate, a moderate-heavy infection is associated with a 0.02/0.23 $=0.09$ reduction in the likelihood of treatment, and this implies a drop in take-up due to infection social effects of only $(0.09) * 1.2 \%=0.1 \%$, rather than the $3.1 \%$ reduction we estimate. Even if eliminating a moderate-heavy infection reduced the likelihood of drug take-up by a truly massive 0.5 on average (rather than the 0.09 we estimate), health externalities would account only for a $(0.5) *(1.2 \%)=0.6 \%$ reduction in take-up, less than one fifth of the overall social effect we estimate.

More evidence against the view that infection externalities are driving the negative social effect is provided by the fact that infection effects are driven entirely by early treatment links with whom the respondent has a “close” social relationship, speaking at least twice per week (Table 6, regression 7, coefficient estimate -0.018), while additional early links with whom the respondent speaks less frequently do not affect infection status (estimate 0.004). Thus “distant” social links appear to have a sizeable (though insignificant) negative impact on adoption decisions (Table 8, regression 4) but no negative effect on infection status, further bolstering the claim that information rather than infection externalities drive the overall social effect.

Pupil transfers among local primary schools are another potential concern, but any resulting bias would likely work against our findings. For example, parents with more health-conscious social contacts - whose children may have been more likely to transfer to early treatment schools in order to receive deworming - may themselves also be more health-conscious and eager to have their own children receive 
treatment. This would bias the estimated social effect upward, in which case our negative social effect estimate would be a bound on the true effect. In any case, the rate of pupil transfers between treatment and comparison schools was low and nearly symmetric in both directions (Miguel and Kremer 2004), suggesting that any transfer bias is likely to be small.

A related identification issue concerns whether social networks measured in 2001 -three years after the program started — were themselves affected by the program. Any extent to which healthconscious individuals became more socially linked to individuals with children in early treatment schools would again lead to an upward bias, working against the negative effect we estimate. However, respondents were statistically no more likely to name early treatment links than links to other schools: the average number of links to early treatment schools is 1.92 , while (Total number of links to project schools) * (Total number of Group 1, 2 pupils / Total number of Groups 1, 2, 3 pupils) =1.91.

\subsection{Parent Attitudes and Knowledge}

Respondents with more early treatment links are significantly more likely to claim that deworming drugs are "not effective” (respondents could choose between "not effective”, "somewhat effective” and "very effective”, Table 9, row 1). ${ }^{30}$ This is consistent with the hypothesis that some people initially thought deworming would provide large net private benefits but learned otherwise from their contacts at early treatment schools. We do not find a significant impact of additional early links on beliefs that deworming drugs are "very effective" although the point estimate is negative (row 2), nor that the drugs have "side effects” (row 3). This last result is evidence against the possibility that drug side effect rumors were driving lower take-up.

Although early treatment links do affect the belief that deworming drugs are "not effective”, they do not affect beliefs that "worms and schistosomiasis are very bad for child health” (Table 9, row 4). However, parents may report what they think the enumerator wants to hear regarding the health

\footnotetext{
${ }^{30}$ A fourth option, "effective, but the worms come back" was rarely chosen by respondents, further indication that few respondents understood the nature of worm infection and transmission.
} 
consequences of worms: 92\% of respondents claimed that helminth infections are "very bad" for child health. The number of early treatment links has no effect on parents' self-reported claim to "know about the ICS deworming program” (row 5), to "know about the effects of worms and schistosomiasis” (row 6), to know the deworming treatment status of their own child (not shown), nor does it affect their objective knowledge of common worm infection symptoms (rows 7 to 10). Most respondents lack even basic knowledge about worm infections, and were only able to name 1.8 of ten common symptoms on average. ${ }^{31}$ Thus, not only did substantial expenditures in worm prevention health education through the original deworming program not affect recipients' behavior directly, as discussed in section 5 above, but these health education messages also completely failed to spread to other community members.

In contrast, the actual number of treated social links, and the number of social links with whom the respondent speaks about deworming, are both positively and significantly related to most deworming attitudes and knowledge outcomes (Table 9), once again highlighting important differences between experimental and nonexperimental methods of estimating social effects. Individuals with unobservably more interest in child health appear to more frequently discuss worms with their social links, who are themselves more likely to have their own children receive treatment. In short, the observed positive correlation in outcomes within social networks in the study area appears to be due to omitted variables rather than actual social effects.

\section{$\underline{\text { 7. Conclusion }}$}

Programs which provide free deworming drugs for primary school students lead to high drug take-up, large reductions in moderate-heavy worm infections, and increased school participation, all at low cost. Most of the deworming program benefit was in the form of externalities due to reduced disease transmission (Miguel and Kremer, 2004). Yet despite this, mass deworming treatment programs like the one we study are rare, and one in four people worldwide still suffer from these easily treated infections.

\footnotetext{
31 The ten symptoms (row 7) include fatigue, anemia, weight loss, stunted growth, stomach ache, bloated stomach, blood in stool, worms in stool, diarrhea, and fever. Parents were asked: "Could you name the symptoms of worm and schistosomiasis infections?” and their unprompted responses were recorded by the enumerator.
} 
One reason for this is that rather than allocate funding on the basis of a standard public finance analysis, development agencies often prefer to fund "sustainable" interventions that do not require continued external funding. We examine several "sustainable" approaches to worm control in this paper, including local cost-recovery, individual mobilization, and health education, and find all were ineffective at combating worms. The fact that take-up fell the more people were exposed to deworming casts doubt on the idea that a temporary program could lead to a sustainable increase in deworming take-up through social learning. These finding suggest that continued subsidies may be needed to control diseases characterized by large positive treatment externalities. In Africa, where half the disease burden is associated with infectious and parasitic diseases (WHO 1999), this means extensive health care subsidies may be needed. More broadly, it may be difficult for external interventions to promote public good provision through voluntary means such as user charges, community mobilization, training, and education.

While we argue that public goods will typically ultimately need to be funded by tax revenue, this paper does not attempt to resolve the question of the extent to which the revenue should come from national governments, local governments, or international donors. That split is largely a distributional question, but also depends on efficiency considerations. The track record of many national governments in providing local public goods is mixed at best, suggesting that political economy problems and principal-agent problems within many governments are serious. Donors could fund public good provision, perhaps contracting with local NGOs to provide these services as in the project we study. They could fund public goods on a long-term basis, or, at a minimum, when they build projects such as roads or wells that will need continued maintenance, they could endow funds earmarked for this purpose, rather than counting on potentially illusory local voluntary contributions.

A third possibility would be for local governments to cover much of the cost. This, however, would require developing countries to decentralize spending decisions to local elected bodies and perhaps giving these bodies the power to collect taxes. This in turn would have major political economy ramifications. It could threaten central government primacy, and potentially foster ethnic and religious 
divisions in diverse societies. Largely unwilling or unable to bring about such radical institutional reforms in less developed countries, donors have instead focused on more cosmetic policy changes, such as encouraging “sustainable” voluntary public goods provision by local communities.

Given that from a public finance standpoint, it is intuitive that it would be difficult to induce voluntary contributions to non-excludable public goods, and that there is little empirical evidence in support of the idea that external interventions can lead to sustainable voluntary public good provision, a natural question is why aid agencies place so much emphasis on financial sustainability. One possibility is that aid agencies want to avoid displacing expenditure by national governments. In the case of deworming that we examine, however, there was no national government expenditure to displace. More broadly, donors could use a variety of means to reduce the likelihood of displacing government expenditures, from conditioning external support on the pattern of spending by the national government; to only funding areas in which governments were not initially operating; to basing funding decisions not on the expenditure of a particular government but rather on those in a set of comparison countries (e.g., all Sub-Saharan African countries), so as to render funding decisions for each country insensitive to that country's own government expenditure. It is far from clear that external donors can best avoid displacing national government expenditure by focusing on "sustainable” projects, since this could lead national governments to neglect cost-effective routine expenditures (for example, on road maintenance) in the hope that donors would fund substituting sustainable expenditures (major road upgrading).

Even if donors wish to fund investment rather than consumption, there is little reason why they should seek projects that are sustainable on a project-by-project basis. A public health project providing subsidized deworming medicine may not be sustainable in itself, but it will help children obtain more education and this will contribute to development for society as a whole.

It seems more likely that the emphasis on financial sustainability by donors reflects principalagent problems within donor agencies and between the agencies and their ultimate funders. If aid agencies are competing for limited donor funds, they may try to outdo each other in claims about what they can achieve. For example, the ultimate funders may find it impossible to distinguish genuine claims 
of temporary health benefits from providing free deworming medicine from largely bogus claims about the permanent benefits of a one-time investment in worm prevention health education. Claims about spectacular project "bang for the buck" typically remain unchallenged since aid agencies are not directly accountable to program beneficiaries through either political mechanisms (e.g., democratic elections) or through the market. Rigorous development program evaluations could potentially provide donors with better information, but unfortunately they remain rare.

Many development professionals may feel they need to promise amazing results in order to appeal to a public grown weary of foreign aid failures. Yet opinion polls in the developed world suggest many would be willing to spend on aid if they believed it actually worked in practice (PIPA 2001). Some of the failures of foreign aid may themselves be due to pursuing the illusion of sustainability. 


\section{$\underline{\text { References }}$}

Adams, E.J., Stephenson, L.S., Latham, M.C., and Kinoti, S.N. (1994). "Physical Activity and Growth of Kenyan School Children with Hookworm, Trichuris trichiura and Ascaris lumbricoides Infections Are Improved after Treatment with Albendazole,” Journal of Nutrition, 124 (8), 1199-1206.

Akwara, Priscilla A. (1996). "Socio-economic Perspectives in Child Health in Kenya: A Strategy for Population Action,” African Anthropology, 3(1), 3-43.

Anderson, R.M., and R.M. May. (1991). Infectious Diseases of Humans. Oxford: New York.

Ariely, Dan, and Kristina Shampan'er. (2004). "Tradeoffs betweens costs and benefits: Lessons from 'the price of 0 '”, unpublished manuscript, MIT.

Azfar, Omar, and Jeffrey Livingston. (2002). "Federalist Disciplines or Local Capture? An Empirical Analysis of Decentralization in Uganda”, unpublished manuscript.

Aziz, K., B. Hoque, K. Hasan, M. Patwary, S. Huttly, M. Arman, and R. Feachem. (1990). "Reduction in Diarrhoeal Diseases in Children in Rural Bangladesh by Environmental and Behavioural Modifications," Transactions of the Royal Society of Tropical Medicine and Hygiene, 84(3), 433-438.

Bandiera, Oriana, and Imran Rasul. (2002). "Social Networks and Technology Adoption in Northern Mozambique”, unpublished manuscript.

Besley, Timothy, and Stephen Coate. (1995). "Group lending, repayment incentives and social collateral”, Journal of Development Economics, 46 (1), 1-18.

Bundy, D.A.P. (1994). “The Global Burden of Intestinal Nematode Disease.” Transactions of the Royal Society of Tropical Medicine and Hygiene, 88, 259-261.

Bundy, D.A.P., and Guyatt, H.L. (1996). "Schools for Health: Focus on Health, Education, and the School-age Child.” Parasitology Today, 12 (8), 1-16.

Burke, M., G. Fournier and K. Prasad. (2003). "Physician Social Networks and Geographical Variation in Care”, unpublished working paper.

Cave, B., and V. Curtis. (1999). "Effectiveness of Promotional Techniques in Environmental Health”, London School of Hygiene and Tropical Medicine, WELL Study Task \# 165.

Cioffi, D., and R. Garner. (1998). "The Effect of Response Options on Decisions and Subsequent Behavior: Sometimes Inaction is Better”, Personality and Social Psychology Bulletin, 24, 463-72.

Conley, Timothy, and Christopher Udry. (2000). “Learning About a New Technology: Pineapple in Ghana”, Economic Growth Center Discussion Paper 817, Yale University.

Corbett, E.L., Butterworth, A.E., Fulford, A.J.C., Ouma, J.H., Sturock, R.F. (1992). "Nutritional Status of Children with Schistosomiasis Mansoni in Two Different areas of Machakos District, Kenya."

Transactions of the Royal Society of Tropical Medicine and Hygiene, 86, 266-273.

Cowden, J., and P. Hotez. (2000). "Mebendazole and Albendazole Treatment of Geohelminth Infections in Children and Pregnant Women,” Pediatric Infectious Disease Journal, 19, 659-60.

Das, Jishnu. 2000. "Do Patients Learn About Doctor Quality: Theory and an Application to India”, unpublished working paper, Harvard University.

Duflo, Esther, and Emmanuel Saez. (2003). “The Role of Information and Social Interactions in Retirement Plan Decisions: Evidence from a Randomized Experiment”, Quarterly Journal of Economics, 118 (3), 267-299. 
Foster, Andrew, and Mark Rosenzweig. (1995). "Learning by Doing and Learning from Others: Human Capital and Technical Change in Agriculture”, Journal of Political Economy, 103, 1176-1209.

Geissler, Wenzel. (1998). “'Worms are Our Life’, Part I: Understandings of Worms and the Body among the Luo of Western Kenya,” Anthropology and Medicine, 5(1), 63-79.

Gertler, Paul, and Jack Molyneaux. (1996). "Pricing Public Health Services: Results from a Social Experiment in Indonesia,” mimeo., RAND, Santa Monica, CA.

Granovetter, Mark. (1973). “The Strength of Weak Ties.” American Journal of Sociology, 78.

Greenwald, A.G., C.G. Carnot, R. Beach, and B. Young. (1987). "Increasing Voting Behavior by Asking People if they Expect to Vote”, Journal of Applied Psychology, 72(2), 315-318.

Haggerty P.A., K. Muladi, B.R. Kirkwood, A. Ashworth, and M. Manunebo (1994), “Community-based Hygiene Education to Reduce Diarrhoeal Disease in Rural Zaire: Impact of the Intervention on Diarrhoeal Morbidity,” International Journal of Epidemiology, 23, 1050-59.

Harms, Gundel, and Hermann Feldmeier. (2002). "HIV Infection and Tropical Parasitic Diseases Deleterious Interactions in Both Directions?”, Tropical Medicine and International Health, 7, 479-88.

Hoque B A., T. Juncker, R.B. Sack, M Ali, and K.M. Aziz. (1996). "Sustainability of a Water, Sanitation and Hygiene Education Project in Rural Bangladesh: a 5-year Follow-up,” Bulletin of the World Health Organization, 74(4), 431-437.

Hotez, P.J., and Pritchard, D.I. (1995). “Hookworm Infection.” Scientific American, June, 68-74.

Hubley, J (1993). Communicating Health - an action guide to health education and health promotion, MacMillan: London.

Jamison, D. T., and J. Leslie. (1990). "Health and Nutrition Considerations in Education Planning II: The Cost and Effectiveness of School-Based Interventions”, Food and Nutrition Bulletin, 12, 204-14.

Kohler, Hans-Peter, Jere Behrman, and Susan Watkins. (2001). "The Density of Social Networks and Fertility Decisions: Evidence from South Nyanza District, Kenya”, Demography, 38, 43-58.

Kremer, Michael, Sylvie Moulin, and Robert Namunyu (2003). "Decentralization: A Cautionary Tale," unpublished working paper, Harvard University.

Lengeler, C. (1999). "From Rio to Iragua: Sustainability versus Efficiency and Equity for Preventative Health Interventions”, Tropical Medicine and International Health, 4(6), 409-411.

Manning, W.G., J.P. Newhouse, N. Duan, E.B. Keeler, A. Leibowitz, and M.S. Marquis. (1987). "Health Insurance and the Demand for Medical Care: Evidence from a Randomized Experiment”, American Economic Review, 77(3), 251-277.

Manski, Charles. (1993). “Identification of Endogenous Social Effects: The Reflection Problem”, Review of Economics Studies, 60(3), 531-542.

McPake, Barbara. (1993). "User Charges for Health Services in Developing Countries: A Review of the Economic Literature,” Social Science and Medicine, 36(11), 1397-1405.

Meuwissen, Liesbeth Emm. (2002). "Problems of cost recovery implementation in district health care: A case study from Niger”, Health Policy and Planning, 17(3), 304-313.

Miguel, Edward, and Mary Kay Gugerty. (2004). "Ethnic Diversity, Social Sanctions, and Public Goods in Kenya”, forthcoming Journal of Public Economics.

Miguel, Edward, and Michael Kremer. (2004). "Worms: Identifying Impacts on Education and Health in the Presence of Treatment Externalities”, Econometrica, 72(1), 159-217. 
Morduch, Jonathan. (1999). “The Microfinance Promise,” Journal of Economic Literature, 37 (4), 15691614.

Munshi, Kaivan, and Jacques Myaux. (2002). "Social Change and Individual Decisions: With an Application to the Demographic Transition”, unpublished working paper, University of Pennsylvania.

Munshi, Kaivan. (2002). "Social Learning in a Heterogeneous Population: Technology Diffusion in the Indian Green Revolution”, forthcoming Journal of Development Economics.

Mwabu, G. J. Mwanzia, W. Liambila. (1995). "User Charges in Government Health Facilities in Kenya: Effect on Attendance and Revenue”, Health Policy and Planning, 10 (2), 164-170.

Ostrom, Elinor. (1990). Governing the Commons: The Evolution of Institutions for Collective Action. New York: Cambridge University Press.

Pant C.R., et al. (1996) "Impact of Nutrition Education and Mega-Dose Vitamin A Supplementation on the Health of Children in Nepal,” Bulletin of the WHO, 74, 533-45.

Partnership for Child Development [PCD]. (1999). “The Cost of Large-scale School Health Programmes which Deliver Anthelmintics in Ghana and Tanzania,” Acta Tropica, 73, 183-204.

Piketty, Thomas. (1995). “Social Mobility and Redistributive Politics”, Quarterly Journal of Economics, 110(3), 551-584.

Pollitt, E. (1990). “Infection: Schistosomiasis”, Malnutrition and Infection in the Classroom, Paris, Unesco: 151-162.

Prince, R. et al. (2001). "Knowledge of Herbal and Pharmaceutical Medicines Among Luo Children in Western Kenya”, Anthropology and Medicine, 8(2/3), 211-235.

Program on International Policy Attitudes (PIPA). (2001). “Americans on Foreign Aid and Hunger: A Study of U.S. Public Attitudes.” Available: http://www.pipa.org/OnlineReports/BFW/other_data.html.

Rabin, Matthew, and Joel Schrag. (1999). "First Impressions Matter: A Model of Confirmatory Bias”, Quarterly Journal of Economics, 114(1), 37-82.

Rosenstein-Rodan, P. N. (1943). "Problems of Industrialization of Eastern and South-Eastern Europe”, Economic Journal, 53, 202-211.

Rostow, W. W. (1960). The Stages of Economic Growth, Cambridge: Cambridge Univ. Press.

Savioli L., Crompton, W.T. and M. Niera (2003). "Use of Anthelminthic Drugs During Pregnancy.” American Journal of Obstetrics and Gynecology, 188:5-6.

Smith, Jennifer K., Alan S. Gerber, and Anton Orlich. (2003). "Self-Prophecy Effects and Voter Turnout: An Experimental Replication”, Political Psychology, 24(3), 593-604.

Steinberg, Laurence, and Elizabeth Cauffman. (1996). "Maturity of Judgement in Adolescence: Psychosocial factors in Adolescent Decision Making”, Law and Human Behavior, 20, 249-272.

Tanner, M. (1998). "Sustainable health development - sustainable health services (editorial)”, Tropical Medicine and International Health, 3(10), 765-766.

Udry, Christopher. (1996). "Gender, Agricultural Productivity, and the Theory of the Household,” Journal of Political Economy, 104(5), 1010-1046.

Utzinger, J., R. Berquist, Xiao Shu-Hua, B.H. Singer, and M. Tanner. (2003). “Sustainable

Schistosomiasis Control - the Way Forward”, Lancet, 362, Dec. 6, 2003, 1932-34.

Warren, K.S., et al. (1993). "Helminth infections." In Disease Control Priorities in Developing Countries (ed. Jamison, D.T., Mosley, W.H., Measham, A.R. and Bobadilla, J.L.), 131-60. Oxford. 
Williamson, John. (1990). “What Washington Means by Policy Reform”, in John Williamson (ed.), Latin American Adjustment: How Much has Happened?, Washington, DC: Institute for International Economics.

Wilson, Leonard. 1992. "The Harambee Movement and Efficient Public Good Provision in Kenya.” Journal of Public Economics 48: 1-19.

World Bank. (1993a). The East Asian Miracle: Economic Growth and Public Policy. Oxford Univ. Press: New York.

World Bank. (1993b). World Development Report: Investing in Health. Oxford Univ. Press: New York.

World Bank. (1994). Better Health in Africa: Experience and Lessons Learned (Development in Practice Series). World Bank: Washington, D.C.

World Bank. (1998). Beyond the Washington Consensus: Institutions Matter. Oxford Univ. Press: New York.

World Bank. (1999). World Development Indicators (www.worldbank.org).

World Bank. (2002). World Development Report 2002: Sustainable Development in a Dynamic World. Oxford Univ. Press: New York.

World Health Organization. (1987). Prevention and Control of intestinal parasitic infections. Report of the WHO Scientific Group. WHO Technical Report Series: 749. WHO, Geneva.

World Health Organization. (1992). Model Describing Information. Drugs used in Parasitic Diseases. WHO, Geneva.

World Health Organization. (1999). The World Health Report 1999. WHO, Geneva. 


\section{Tables and Figures}

Table 1: Cost-sharing Summary Statistics

\begin{tabular}{lccc}
\hline \hline & Mean & Std dev. & Obs. \\
\hline Panel A: Deworming Treatment Take-up & & & \\
Took deworming drugs in 2001 (Group 2 and 3) & 0.61 & 0.49 & 1678 \\
Proportion deworming drug take-up in 2001, respondent's own school & 0.61 & 0.28 & 1678 \\
Took deworming drugs in 2001, free treatment schools & 0.75 & 0.43 & 1251 \\
Took deworming drugs in 2001, cost-sharing schools & 0.19 & 0.39 & 427 \\
Provided parental consent for deworming drugs in 2001 & 0.76 & 0.43 & 1678 \\
Panel B: Cost-Sharing and Verbal Commitment Interventions & & & \\
Cost-sharing school indicator & 0.25 & 0.43 & 1678 \\
Cost-sharing school indicator, albendazole only treatment & 0.17 & 0.38 & 1678 \\
Cost-sharing school indicator, albendazole and praziquantel treatment & 0.08 & 0.27 & 1678 \\
Effective price of deworming per child (Kenyan shillings) & 6.3 & 15.7 & 1678 \\
Verbal commitment intervention indicator & 0.43 & 0.49 & 3164 \\
\hline \hline
\end{tabular}

Notes: From 2001 PSDP Parent and Pupil Surveys and 2001 administrative records. The sample for the verbal commitment intervention indicator is the 2001 Pupil Survey. 
Table 2: The Impact of Cost-sharing

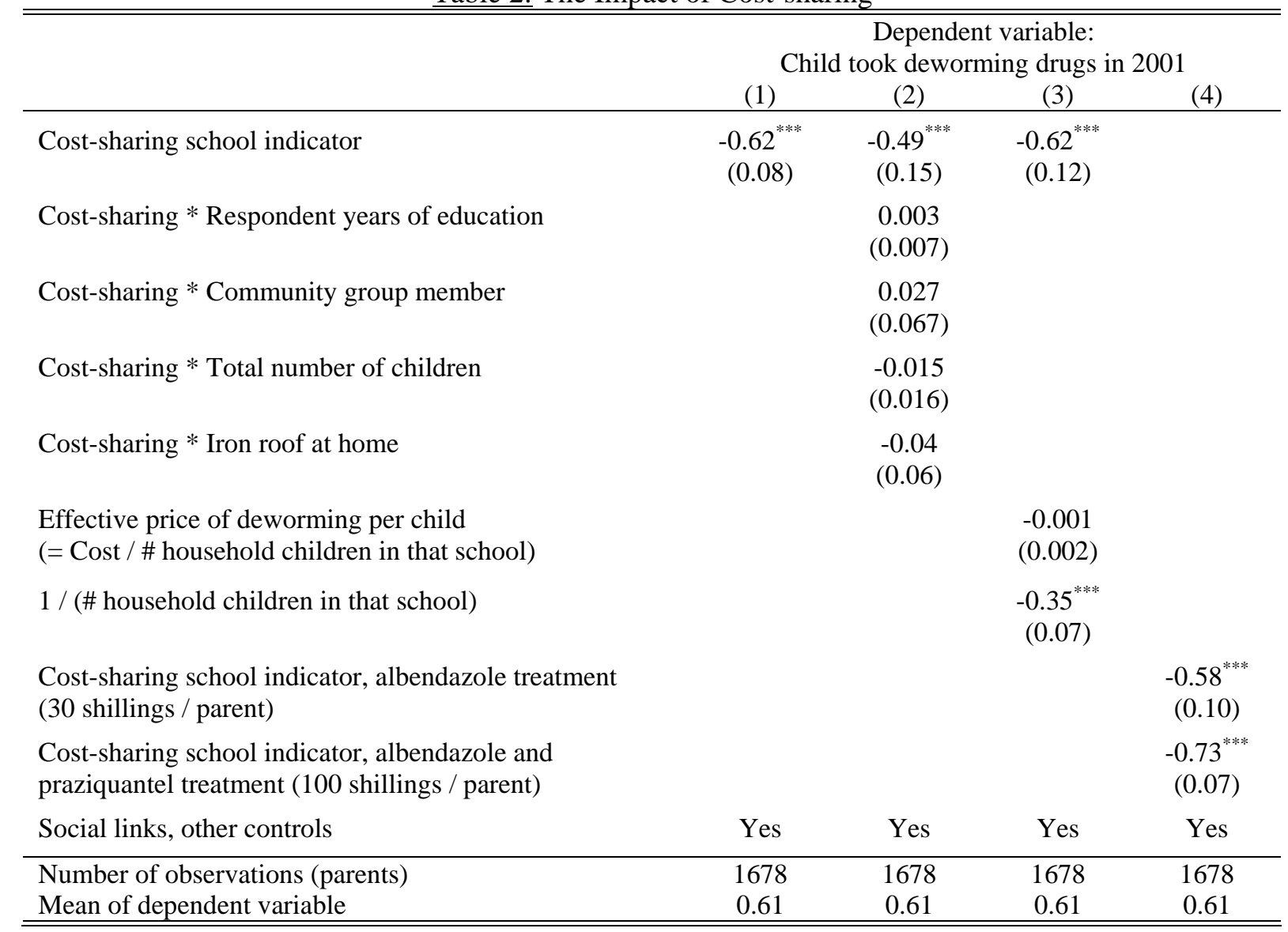

Notes: Data from 2001 Parent Survey, and 2001 administrative records. Marginal probit coefficient estimates are presented. Robust standard errors in parentheses. Disturbance terms are clustered within schools. Significantly different than zero at $99(* * *), 95(* *)$, and $90(*)$ percent confidence. Social links controls include total number of links, number of links to Group 1, 2, 3 schools (not own school), and number of links to non-program schools (as in Table 7 below). Other controls include respondent years of education, community group member indicator variable, total number of children in the household, iron roof at home indicator variable, and distance from home to school in $\mathrm{km}$, as well as the Group 2 indicator (as in Table 7 below). We cannot reject that the two terms in regression 4 are equal (p-value=0.17). 
Table 3: The Impact of a Verbal Commitment Intervention

\begin{tabular}{|c|c|c|c|}
\hline & \multicolumn{3}{|c|}{$\begin{array}{c}\text { Dependent variable: } \\
\text { Child took deworming drugs in } 2001\end{array}$} \\
\hline & (1) & (2) & (3) \\
\hline Verbal commitment intervention indicator & $\begin{array}{l}-0.014 \\
(0.021)\end{array}$ & $\begin{array}{l}-0.013 \\
(0.021)\end{array}$ & $\begin{array}{l}-0.023 \\
(0.145)\end{array}$ \\
\hline Pupil age & & $\begin{array}{l}-0.004 \\
(0.006)\end{array}$ & $\begin{array}{l}-0.003 \\
(0.006)\end{array}$ \\
\hline Pupil female & & $\begin{array}{l}-0.048^{* *} \\
(0.024)\end{array}$ & $\begin{array}{l}-0.050 \\
(0.035)\end{array}$ \\
\hline Verbal commitment intervention indicator *Age & & & $\begin{array}{l}-0.003 \\
(0.010)\end{array}$ \\
\hline Verbal commitment intervention indicator *Female & & & $\begin{array}{c}0.005 \\
(0.006)\end{array}$ \\
\hline Social links, other controls & Yes & Yes & Yes \\
\hline Number of observations (pupils) & 3164 & 3164 & 3164 \\
\hline Mean of dependent variable & 0.54 & 0.54 & 0.54 \\
\hline
\end{tabular}

Notes: Data from 2001 Parent and Pupil Surveys, and administrative records. Marginal probit coefficient estimates are presented, robust standard errors in parentheses. Disturbance terms are clustered within schools. Significantly different than zero at $99(* * *), 95(* *)$, and $90(*)$ percent confidence. Social links controls are described in Miguel and Kremer (2003). Other controls include respondent years of education, community group member indicator variable, total number of children, iron roof at home indicator variable, and distance from home to school in $\mathrm{km}$, as well as the Group 2 and Cost-sharing school indicators. Summary statistics from the 2001 Pupil Questionnaire (Mean [s.d.]): Pupil age (12.9 [2.3]), Pupil female indicator (0.23 [0.42]) (older girls were dropped from the sample because they were not eligible for deworming, due to the potential embryotoxicity of the drugs). 


\begin{tabular}{|c|c|c|c|}
\hline & Group 1 & Group 2 & $\frac{\text { Group } 1-}{\text { Group } 2}$ \\
\hline \multicolumn{4}{|l|}{ Panel A: Health Behaviors, all pupils (Grades 3-8) } \\
\hline Clean (observed by field worker), 1999 & 0.59 & 0.60 & $\begin{array}{l}-0.01 \\
(0.02)\end{array}$ \\
\hline Wears shoes (observed by field worker), 1999 & 0.24 & 0.26 & $\begin{array}{l}-0.02 \\
(0.03)\end{array}$ \\
\hline $\begin{array}{l}\text { Days contact with fresh water in past week } \\
\text { (self-reported), } 1999\end{array}$ & 2.4 & 2.2 & $\begin{array}{c}0.2 \\
(0.3)\end{array}$ \\
\hline \multicolumn{4}{|l|}{ Panel B: Health behaviors, girls $\geq 13$ years old } \\
\hline Clean (observed by field worker), 1999 & 0.75 & 0.77 & $\begin{array}{l}-0.02 \\
(0.02)\end{array}$ \\
\hline Wears shoes (observed by field worker), 1999 & 0.39 & 0.42 & $\begin{array}{l}-0.03 \\
(0.06)\end{array}$ \\
\hline $\begin{array}{l}\text { Days contact with fresh water in past week } \\
\text { (self-reported), } 1999\end{array}$ & 2.3 & 2.2 & $\begin{array}{c}0.0 \\
(0.3)\end{array}$ \\
\hline Panel C: Health behaviors, all pupils (Grades 3-8) & $\begin{array}{c}\begin{array}{c}\text { Overall cross- } \\
\text { school externality }\end{array} \\
\text { effect for Group 2 }\end{array}$ & & \\
\hline Clean (observed by field worker), 1999 & $\begin{array}{c}0.09 \\
(0.21)\end{array}$ & & \\
\hline Wears shoes (observed by field worker), 1999 & $\begin{array}{l}-0.01 \\
(0.08)\end{array}$ & & \\
\hline $\begin{array}{l}\text { Days contact with fresh water in past week } \\
\text { (self-reported), } 1999\end{array}$ & $\begin{array}{c}0.98 \\
(0.68)\end{array}$ & & \\
\hline
\end{tabular}

Notes: These results use the data from Miguel and Kremer (2004). These are averages of individual-level data for grade 3-8 pupils; disturbance terms are clustered within schools. Robust standard errors in parentheses. Significantly different than zero at $99\left({ }^{* * *}\right), 95(* *)$, and $90(*)$ percent confidence.

The effects in Panel $\mathrm{C}$ are the result of a regression in which the dependent variable is the change in the health behavior between 1998 and 1999 (school average), and the local density of Group 1 pupils within $3 \mathrm{~km}$ (per 1000 pupils), Group 1 pupils within 3-6 km (per 1000 pupils), Total pupils within $3 \mathrm{~km}$ (per 1000 pupils) and Total pupils within 3-6 km (per 1000 pupils) are the key explanatory variables (as in Miguel and Kremer 2004). Grade indicators, school assistance controls (for other NGO programs), and the average school district mock exam score are additional explanatory variables. 


\begin{tabular}{|c|c|c|c|}
\hline & Mean & Std dev. & Obs. \\
\hline \multicolumn{4}{|l|}{ Panel A: Parent Social Links (Round 1 and Round 2 Data) } \\
\hline Total & 10.2 & 3.4 & 1678 \\
\hline With children in own school & 4.4 & 2.8 & 1678 \\
\hline With children not in Group 1, 2, or 3 schools & 3.0 & 2.4 & 1678 \\
\hline With children in Group 1, 2, 3 schools - not own school & 2.8 & 2.4 & 1678 \\
\hline With children in Group 1, 2 schools - not own school (“early treatment”) & 1.9 & 2.0 & 1678 \\
\hline With children in Group 1 schools - not own school & 0.9 & 1.4 & 1678 \\
\hline Proportion with children in early treatment schools & 0.66 & 0.37 & 1358 \\
\hline $\begin{array}{l}\text { With children in early treatment schools, with whom respondent speaks at least } \\
\text { twice per week ("Close Links”) }\end{array}$ & 1.2 & 1.6 & 1678 \\
\hline $\begin{array}{l}\text { With children in early treatment schools, with whom respondent speaks less than } \\
\text { twice per week ("Distant Links") }\end{array}$ & 0.7 & 1.1 & 1678 \\
\hline With children in early treatment schools, high deworming take-up 1999 & 0.95 & 1.41 & 1678 \\
\hline With children in early treatment schools, low deworming take-up 1999 & 0.96 & 1.47 & 1678 \\
\hline $\begin{array}{l}\text { With children in early treatment schools, large difference in school participation } \\
\text { between treated and untreated } 1999\end{array}$ & 0.99 & 1.47 & 1678 \\
\hline $\begin{array}{l}\text { With children in early treatment schools, small difference in school participation } \\
\text { treated and untreated } 1999\end{array}$ & 0.90 & 1.36 & 1678 \\
\hline \multicolumn{4}{|l|}{ Panel B: Parent Social Links (Round 2 Data) } \\
\hline With children in own school who received deworming & 1.5 & 2.2 & 886 \\
\hline With children in early treatment schools who received deworming & 0.39 & 1.02 & 886 \\
\hline $\begin{array}{l}\text { With children in early treatment schools who received deworming and had "good } \\
\text { effects" (according to respondent) }\end{array}$ & 0.26 & 0.90 & 886 \\
\hline $\begin{array}{l}\text { With children in early treatment schools who received deworming and had "side } \\
\text { effects" (according to respondent) }\end{array}$ & 0.02 & 0.20 & 886 \\
\hline $\begin{array}{l}\text { With children in early treatment schools who received deworming, respondent does } \\
\text { not know effects }\end{array}$ & 0.09 & 0.39 & 886 \\
\hline $\begin{array}{l}\text { With children in early treatment schools, respondent does not know whether they } \\
\text { received deworming }\end{array}$ & 1.89 & 2.06 & 886 \\
\hline With children in early treatment schools who did not receive deworming & 0.16 & 0.57 & 886 \\
\hline
\end{tabular}

Notes: From 2001 Parent Questionnaire and NGO administrative records. The "Proportion in early treatment schools" variables exclude respondents with no links to program schools (other than their own), hence the reduced sample. 
Table 6: Validating the randomization (Group 2 and Group 3 households)

\begin{tabular}{|c|c|c|c|c|c|c|c|}
\hline \multirow[b]{3}{*}{ Explanatory variables: } & \multicolumn{7}{|c|}{ Dependent variable: } \\
\hline & \multirow{2}{*}{$\begin{array}{c}\frac{\text { Respondent }}{\text { years of }} \\
\frac{\text { education }}{\text { OLS }} \\
(1)\end{array}$} & \multirow{2}{*}{$\begin{array}{l}\text { Community } \\
\text { group } \\
\frac{\text { member }}{\text { Probit }} \\
(2)\end{array}$} & \multirow{2}{*}{$\frac{\frac{\text { Total }}{\text { number of }}}{\frac{\text { children }}{\text { OLS }}}$} & \multirow{2}{*}{$\begin{array}{l}\text { Iron roof at } \\
\text { home } \\
\text { Probit } \\
(4)\end{array}$} & \multirow{2}{*}{$\begin{array}{c}\frac{\underline{\text { Distance }}}{\text { home to }} \\
\frac{\underline{\text { school }(\mathrm{km})}}{\text { OLS }} \\
(5)\end{array}$} & \multicolumn{2}{|c|}{$\frac{\text { Moderate-heavy }}{\underline{\text { infection, } 2001}}$} \\
\hline & & & & & & $\begin{array}{c}\text { Probit } \\
(6)\end{array}$ & $\begin{array}{c}\text { Probit } \\
(7)\end{array}$ \\
\hline $\begin{array}{l}\text { \# Parent links with children in early treatment schools (Group } \\
\text { 1, 2, not own school) }\end{array}$ & $\begin{array}{c}0.07 \\
(0.08)\end{array}$ & $\begin{array}{l}-0.008 \\
(0.012)\end{array}$ & $\begin{array}{l}-0.01 \\
(0.06)\end{array}$ & $\begin{array}{l}0.025^{* *} \\
(0.012)\end{array}$ & $\begin{array}{l}-0.18 \\
(0.12)\end{array}$ & $\begin{array}{l}-0.012 \\
(0.018)\end{array}$ & \\
\hline $\begin{array}{l}\text { \# Parent links with children in early treatment schools, with } \\
\text { whom respondent speaks at least twice/week }\end{array}$ & & & & & & & $\begin{array}{l}-0.018 \\
(0.023)\end{array}$ \\
\hline $\begin{array}{l}\text { \# Parent links with children in early treatment schools, with } \\
\text { whom respondent speaks less than twice/week }\end{array}$ & & & & & & & $\begin{array}{c}0.004 \\
(0.021)\end{array}$ \\
\hline $\begin{array}{l}\text { \# Parent links with children in Group 1, 2, or } 3 \text { schools, not } \\
\text { own school }\end{array}$ & $\begin{array}{c}0.11 \\
(0.07)\end{array}$ & $\begin{array}{c}0.013 \\
(0.011)\end{array}$ & $\begin{array}{c}-0.029 \\
(0.054)\end{array}$ & $\begin{array}{c}-0.009 \\
(0.012)\end{array}$ & $\begin{array}{c}0.14 \\
(0.11)\end{array}$ & $\begin{array}{c}-0.001 \\
(0.015)\end{array}$ & $\begin{array}{c}-0.002 \\
(0.014)\end{array}$ \\
\hline \# Parent links with children not in Group 1, 2, or 3 schools & $\begin{array}{l}0.07^{* *} \\
(0.03)\end{array}$ & $\begin{array}{l}0.018^{* * *} \\
(0.006)\end{array}$ & $\begin{array}{c}-0.043 \\
(0.030)\end{array}$ & $\begin{array}{c}0.009 \\
(0.006)\end{array}$ & $\begin{array}{c}0.02 \\
(0.03)\end{array}$ & $\begin{array}{c}-0.010 \\
(0.009)\end{array}$ & $\begin{array}{c}-0.009 \\
(0.009)\end{array}$ \\
\hline \# Parent links, total & $\begin{array}{l}0.13^{* * *} \\
(0.04)\end{array}$ & $\begin{array}{c}0.007 \\
(0.006)\end{array}$ & $\begin{array}{l}0.059^{* *} \\
(0.028)\end{array}$ & $\begin{array}{l}-0.011^{*} \\
(0.006)\end{array}$ & $\begin{array}{l}-0.01 \\
(0.03)\end{array}$ & $\begin{array}{c}0.003 \\
(0.008)\end{array}$ & $\begin{array}{c}0.003 \\
(0.007)\end{array}$ \\
\hline Cost-sharing school indicator & $\begin{array}{c}0.12 \\
(0.30)\end{array}$ & $\begin{array}{c}0.00 \\
(0.04)\end{array}$ & $\begin{array}{c}0.07 \\
(0.23)\end{array}$ & $\begin{array}{c}0.02 \\
(0.06)\end{array}$ & $\begin{array}{c}1.3 \\
(0.9)\end{array}$ & $\begin{array}{c}0.07 \\
(0.11)\end{array}$ & $\begin{array}{c}0.07 \\
(0.11)\end{array}$ \\
\hline Group 2 school indicator & $\begin{array}{l}-0.46 \\
(0.29)\end{array}$ & $\begin{array}{l}-0.03 \\
(0.04)\end{array}$ & $\begin{array}{c}0.13 \\
(0.19)\end{array}$ & $\begin{array}{c}0.01 \\
(0.05)\end{array}$ & $\begin{array}{l}-0.03 \\
(0.28)\end{array}$ & $\begin{array}{c}-0.22^{* * *} \\
(0.07)\end{array}$ & $\begin{array}{c}-0.22^{* * *} \\
(0.07)\end{array}$ \\
\hline Socio-economic controls (excluding dependent variable) & Yes & Yes & Yes & Yes & Yes & Yes & Yes \\
\hline $\mathrm{R}^{2}$ & 0.06 & - & 0.01 & - & 0.10 & - & - \\
\hline Root MSE & 3.8 & - & 2.3 & - & 1.9 & - & - \\
\hline Number of observations (parents) & 1678 & 1678 & 1678 & 1678 & 1678 & 575 & 575 \\
\hline Mean (s.d.) of dependent variable & $4.6(3.9)$ & $0.58(0.49)$ & $5.5(2.3)$ & $0.61(0.49)$ & $1.7(2.0)$ & 0.27 & $.45)$ \\
\hline
\end{tabular}

Notes: Data from 2001 Parent Survey, 2001 Parasitological Survey, and 2001 administrative records. Robust standard errors in parentheses. Disturbance terms are clustered within schools. Significantly different than zero at $99(* * *), 95(* *)$, and $90\left(^{*}\right)$ percent confidence. The socioeconomic controls include Respondent years of education, Community group member, Total number of children, Iron roof at home, and Distance from home to school (but when any of these is the dependent variable, it is not included as an explanatory variable). In regression 7, the difference between the effects of close and distant links becomes even larger if (\# Parent links with children in Group 1, 2, or 3 schools, not own school, with whom the respondent speaks at least twice/week) and (\# Parent links with children in Group 1, 2, or 3 schools, not own school, with whom the respondent speaks less than twice/week) are included as controls instead of (\# Parent links with children in Group 1, 2, or 3 schools, not own school), although there is no statistically significant difference with the coefficient estimates presented above. 


\begin{tabular}{|c|c|c|c|}
\hline \multirow[b]{2}{*}{ Explanatory variables: } & \multicolumn{3}{|c|}{$\begin{array}{c}\text { Dependent variable: } \\
\text { Child took deworming drugs in } 2001\end{array}$} \\
\hline & $\begin{array}{c}\text { Probit } \\
(1)\end{array}$ & $\begin{array}{c}\text { Probit } \\
(2)\end{array}$ & $\begin{array}{c}\text { Probit } \\
(3)\end{array}$ \\
\hline $\begin{array}{l}\text { Proportion deworming drug take-up in 2001, respondent's own school } \\
\text { (not including respondent) }\end{array}$ & $\begin{array}{l}0.84^{* * *} \\
(0.11)\end{array}$ & & \\
\hline $\begin{array}{l}\text { \# Parent links with children in respondent's own school whose children } \\
\text { received deworming }\end{array}$ & & $\begin{array}{c}0.015 \\
(0.011)\end{array}$ & \\
\hline $\begin{array}{l}\text { \# Parent links with children in early treatment schools whose children } \\
\text { received deworming and had "good effects" }\end{array}$ & & & $\begin{array}{c}0.004 \\
(0.021)\end{array}$ \\
\hline $\begin{array}{l}\text { \# Parent links with children in early treatment schools whose children } \\
\text { received deworming and had "side effects" }\end{array}$ & & & $\begin{array}{l}-0.112 \\
(0.082)\end{array}$ \\
\hline $\begin{array}{l}\text { \# Parent links with children in early treatment schools whose children } \\
\text { received deworming and respondent does not know effects }\end{array}$ & & & $\begin{array}{c}0.006 \\
(0.046)\end{array}$ \\
\hline $\begin{array}{l}\text { \# Parent links with children in early treatment schools whose children } \\
\text { did not receive deworming }\end{array}$ & & & $\begin{array}{l}-0.007 \\
(0.028)\end{array}$ \\
\hline $\begin{array}{l}\text { \# Parent links in with children in early treatment schools, respondent } \\
\text { does not know whether they received deworming }\end{array}$ & & & $\begin{array}{l}-0.013 \\
(0.016)\end{array}$ \\
\hline Social links, other controls & Yes & Yes & Yes \\
\hline Number of observations (parents) & 1678 & 886 & 886 \\
\hline
\end{tabular}

Notes: Data from 2001 Parent Survey, and 2001 administrative records. Marginal probit coefficient estimates are presented. Robust standard errors in parentheses. Disturbance terms are clustered within schools. Significantly different than zero at $99(* * *), 95(* *)$, and $90(*)$ percent confidence. Social links controls include total number of parent links, number of parent links to Group 1, 2, 3 schools (not own school), and number of links parent to nonprogram schools. Other controls include respondent years of education, community group member indicator variable, total number of children, iron roof at home indicator variable, and distance from home to school in $\mathrm{km}$, as well as the Group 2 indicator and Cost-sharing school indicator.

Regression 1 presents results from Round 1 and Round 2 of the 2001 Parent Survey, and regressions 2 and 3 present results from Round 2 alone, since only Round 2 has detailed information regarding deworming treatment impacts on social links. In regression 3, we cannot reject that the coefficient estimates on (\# Links with children in early treatment schools whose children received deworming and had good effects) and on (\# Links with children in early treatment schools whose children received deworming and had side effects) are equal ( $p$-value $=0.22$ ). 
Table 8: Experimental Social Effect Estimates (Groups 2 and 3)

\begin{tabular}{|c|c|c|c|c|c|}
\hline \multirow[b]{2}{*}{ Explanatory variables: } & \multicolumn{5}{|c|}{$\begin{array}{c}\text { Dependent variable: } \\
\text { Child took deworming drugs in } 2001\end{array}$} \\
\hline & $\begin{array}{l}\text { Probit } \\
(1)\end{array}$ & $\begin{array}{c}\text { Probit } \\
(2)\end{array}$ & $\begin{array}{c}\text { Probit } \\
(3)\end{array}$ & $\begin{array}{l}\text { Probit } \\
(4)\end{array}$ & $\begin{array}{l}\text { Probit } \\
(5)\end{array}$ \\
\hline $\begin{array}{l}\text { \# Parent links with children in early treatment schools } \\
\text { (Groups } 1 \text { and 2, not own school) }\end{array}$ & $\begin{array}{c}-0.031^{* *} \\
(0.014)\end{array}$ & $\begin{array}{l}-0.041^{* *} \\
(0.017)\end{array}$ & & & $\begin{array}{l}-0.002 \\
(0.018)\end{array}$ \\
\hline $\begin{array}{l}\text { \# Parent links with children in early treatment schools } \\
\text { * Group } 2 \text { school indicator }\end{array}$ & & $\begin{array}{c}0.018 \\
(0.029)\end{array}$ & & & \\
\hline $\begin{array}{l}\text { Proportion parent links with children in early treatment } \\
\text { schools }\end{array}$ & & & $\begin{array}{l}-0.098^{* *} \\
(0.045)\end{array}$ & & \\
\hline $\begin{array}{l}\text { \# Parent links with children in early treatment schools, } \\
\text { with whom respondent speaks at least twice/week }\end{array}$ & & & & $\begin{array}{l}-0.030^{* *} \\
(0.016)\end{array}$ & \\
\hline $\begin{array}{l}\text { \# Parent links with children in early treatment schools, } \\
\text { with whom respondent speaks less than twice/week }\end{array}$ & & & & $\begin{array}{l}-0.033 \\
(0.033)\end{array}$ & \\
\hline $\begin{array}{l}\text { \# Parent links with children in early treatment schools } \\
\text { * Respondent years of education }\end{array}$ & & & & & $\begin{array}{l}-0.0062^{*} \\
(0.0032)\end{array}$ \\
\hline $\begin{array}{l}\text { \# Parent links with children in Group 1, 2, or } 3 \text { schools, } \\
\text { not own school, with whom speaks at least twice/week }\end{array}$ & & & & $\begin{array}{c}0.008 \\
(0.012)\end{array}$ & \\
\hline $\begin{array}{l}\text { \# Parent links with children in Group 1, 2, or } 3 \text { schools, } \\
\text { not own school, with whom speaks less than twice/week }\end{array}$ & & & & $\begin{array}{c}0.025 \\
(0.028)\end{array}$ & \\
\hline $\begin{array}{l}\text { \# Parent links with children in Group 1, 2, or } 3 \text { schools, } \\
\text { not own school }\end{array}$ & $\begin{array}{c}0.013 \\
(0.011)\end{array}$ & $\begin{array}{c}0.013 \\
(0.017)\end{array}$ & $\begin{array}{c}-0.006 \\
(0.009)\end{array}$ & & $\begin{array}{l}-0.014 \\
(0.014)\end{array}$ \\
\hline \# Parent links with children not in Group 1, 2, or 3 schools & $\begin{array}{c}-0.008 \\
(0.007)\end{array}$ & $\begin{array}{c}-0.008 \\
(0.009)\end{array}$ & $\begin{array}{c}-0.005 \\
(0.007)\end{array}$ & $\begin{array}{c}-0.008 \\
(0.007)\end{array}$ & $\begin{array}{l}-0.008 \\
(0.011)\end{array}$ \\
\hline \# Parent links, total & $\begin{array}{c}0.019^{* * *} \\
(0.005)\end{array}$ & $\begin{array}{c}0.029^{* * *} \\
(0.007)\end{array}$ & $\begin{array}{l}0.021^{* * *} \\
(0.007)\end{array}$ & $\begin{array}{l}0.018^{* * *} \\
(0.005)\end{array}$ & $\begin{array}{c}0.013 \\
(0.008)\end{array}$ \\
\hline Respondent years of education & $\begin{array}{c}0.003 \\
(0.003)\end{array}$ & $\begin{array}{c}0.003 \\
(0.003)\end{array}$ & $\begin{array}{c}0.002 \\
(0.004)\end{array}$ & $\begin{array}{c}0.002 \\
(0.003)\end{array}$ & $\begin{array}{l}-0.016 \\
(0.012)\end{array}$ \\
\hline Community group member & $\begin{array}{c}0.029 \\
(0.025)\end{array}$ & $\begin{array}{c}0.033 \\
(0.026)\end{array}$ & $\begin{array}{c}0.038 \\
(0.029)\end{array}$ & $\begin{array}{c}0.031 \\
(0.025)\end{array}$ & $\begin{array}{c}0.025 \\
(0.025)\end{array}$ \\
\hline Total number of children & $\begin{array}{c}0.005 \\
(0.006)\end{array}$ & $\begin{array}{c}0.006 \\
(0.006)\end{array}$ & $\begin{array}{c}0.005 \\
(0.007)\end{array}$ & $\begin{array}{c}0.005 \\
(0.006)\end{array}$ & $\begin{array}{c}0.006 \\
(0.006)\end{array}$ \\
\hline Iron roof at home & $\begin{array}{c}0.010 \\
(0.027)\end{array}$ & $\begin{array}{c}0.007 \\
(0.027)\end{array}$ & $\begin{array}{c}0.010 \\
(0.032)\end{array}$ & $\begin{array}{c}0.010 \\
(0.027)\end{array}$ & $\begin{array}{c}0.008 \\
(0.027)\end{array}$ \\
\hline Distance home to school (km) & $\begin{array}{c}-0.018^{* *} \\
(0.009)\end{array}$ & $\begin{array}{l}-0.018^{* *} \\
(0.009)\end{array}$ & $\begin{array}{c}-0.014 \\
(0.010)\end{array}$ & $\begin{array}{l}-0.017^{*} \\
(0.009)\end{array}$ & $\begin{array}{c}-0.018^{* *} \\
(0.009)\end{array}$ \\
\hline Group 2 school indicator & $\begin{array}{c}0.01 \\
(0.05)\end{array}$ & $\begin{array}{l}0.20^{* *} \\
(0.09)\end{array}$ & $\begin{array}{c}0.01 \\
(0.05)\end{array}$ & $\begin{array}{c}0.01 \\
(0.05)\end{array}$ & $\begin{array}{c}0.01 \\
(0.05)\end{array}$ \\
\hline Cost-sharing school indicator & $\begin{array}{c}-0.62^{* * *} \\
(0.08)\end{array}$ & $\begin{array}{c}-0.62^{* * *} \\
(0.08)\end{array}$ & $\begin{array}{c}-0.62^{* * *} \\
(0.09)\end{array}$ & $\begin{array}{c}-0.063^{* * *} \\
(0.08)\end{array}$ & $\begin{array}{c}-0.63^{* * *} \\
(0.08)\end{array}$ \\
\hline Number of observations (parents) & 1678 & 1678 & 1358 & 1678 & 1678 \\
\hline Mean of dependent variable & 0.61 & 0.61 & 0.61 & 0.61 & 0.61 \\
\hline
\end{tabular}

Notes: Data from 2001 Parent Survey, and 2001 administrative records. Marginal probit coefficient estimates are presented. Robust standard errors in parentheses. Disturbance terms are clustered within schools. Significantly different than zero at $99(* * *), 95(* *)$, and $90(*)$ percent confidence. 
Regression 2 also includes interaction terms (\# Parent social links with children in Group 1, 2, or 3 schools, not own school)*(Group 2), (\# Parent social links with children not in Group 1, 2, or 3 schools)*(Group 2), and (\# Parent social links, total)*(Group 2).

Regression 3 excludes parents for which (\# Parent social links with children in Group 1, 2, or 3 schools, not own school $)=0$, since the proportion of links is undefined in that case, leading to the reduction in sample size.

Regression 5 also includes interaction terms (\# Parent social links with children in Group 1, 2, or 3 schools, not own school)*(Respondent years of education) and (\# Parent social links with children not in Group 1, 2, or 3 schools)*(Respondent years of education). 
Table 9: Effects on Deworming Attitudes and Knowledge

\begin{tabular}{|c|c|c|c|c|}
\hline Dependent variable: & $\begin{array}{c}\text { Estimate on } \\
\text { \# Parent links with } \\
\text { children in early } \\
\text { treatment schools } \\
\\
\text { [Experimental] }\end{array}$ & $\begin{array}{c}\text { Estimate on } \\
\text { \# Parent links with } \\
\text { children in early } \\
\text { treatment schools } \\
\text { whose children } \\
\text { received deworming } \\
\\
\text { [Non-experimental] }\end{array}$ & $\begin{array}{c}\text { Estimate on } \\
\text { \# Parent links with } \\
\text { children in early } \\
\text { treatment schools } \\
\text { with whom } \\
\text { respondent spoke } \\
\text { about deworming } \\
\text { [Non-experimental] }\end{array}$ & $\begin{array}{l}\text { Mean } \\
\text { dep. var. }\end{array}$ \\
\hline $\begin{array}{l}\text { Panel A: Attitudes } \\
\text { 1) Parent thinks deworming drugs } \\
\text { "not effective" }\end{array}$ & $\begin{array}{l}0.017^{* *} \\
(0.007)\end{array}$ & $\begin{array}{c}0.013 \\
(0.008)\end{array}$ & $\begin{array}{l}0.009^{* *} \\
(0.004)\end{array}$ & 0.12 \\
\hline $\begin{array}{l}\text { 2) Parent thinks deworming drugs } \\
\text { "very effective" }\end{array}$ & $\begin{array}{l}-0.007 \\
(0.010)\end{array}$ & $\begin{array}{l}0.026^{* *} \\
(0.013)\end{array}$ & $\begin{array}{l}0.040^{* * *} \\
(0.007)\end{array}$ & 0.43 \\
\hline $\begin{array}{l}\text { 3) Parent thinks deworming drugs } \\
\text { have "side effects" }\end{array}$ & $\begin{array}{c}0.000 \\
(0.003)\end{array}$ & $\begin{array}{l}-0.001 \\
(0.003)\end{array}$ & $\begin{array}{c}0.003^{*} \\
(0.002)\end{array}$ & 0.04 \\
\hline $\begin{array}{l}\text { 4) Parent thinks worms and } \\
\text { schisto. "very bad" for child health }\end{array}$ & $\begin{array}{l}-0.001 \\
(0.006)\end{array}$ & $\begin{array}{l}-0.004 \\
(0.006)\end{array}$ & $\begin{array}{l}-0.006^{*} \\
(0.003)\end{array}$ & 0.92 \\
\hline $\begin{array}{l}\text { Panel B: Knowledge } \\
\text { 5) Parent "knows about ICS } \\
\text { deworming program" }\end{array}$ & $\begin{array}{c}0.004 \\
(0.011)\end{array}$ & $\begin{array}{l}0.050^{* * *} \\
(0.014)\end{array}$ & $\begin{array}{l}0.055^{* * *} \\
(0.011)\end{array}$ & 0.70 \\
\hline $\begin{array}{l}\text { 6) Parent "knows about the effects } \\
\text { of worms and schistosomiasis" }\end{array}$ & $\begin{array}{l}-0.001 \\
(0.013)\end{array}$ & $\begin{array}{l}0.045^{* * *} \\
(0.013)\end{array}$ & $\begin{array}{l}0.039^{* * *} \\
(0.009)\end{array}$ & 0.68 \\
\hline $\begin{array}{l}\text { 7) Number of infection symptoms } \\
\text { parents able to name }(0-10)\end{array}$ & $\begin{array}{l}-0.006 \\
(0.005)\end{array}$ & $\begin{array}{l}0.018^{* *} \\
(0.008)\end{array}$ & $\begin{array}{l}0.010^{* *} \\
(0.005)\end{array}$ & 1.8 \\
\hline $\begin{array}{l}\text { 8) Parent able to name "fatigue" as } \\
\text { symptom of infection }\end{array}$ & $\begin{array}{l}-0.004 \\
(0.010)\end{array}$ & $\begin{array}{l}0.028^{* * *} \\
(0.009)\end{array}$ & $\begin{array}{l}0.021^{* * *} \\
(0.006)\end{array}$ & 0.20 \\
\hline $\begin{array}{l}\text { 9) Parent able to name "anemia" as } \\
\text { symptom of infection }\end{array}$ & $\begin{array}{c}0.005 \\
(0.009)\end{array}$ & $\begin{array}{l}-0.003 \\
(0.011)\end{array}$ & $\begin{array}{l}0.010^{* *} \\
(0.005)\end{array}$ & 0.22 \\
\hline $\begin{array}{l}\text { 10) Parent able to name "weight } \\
\text { loss" as symptom of infection }\end{array}$ & $\begin{array}{c}0.002 \\
(0.006)\end{array}$ & $\begin{array}{c}0.004 \\
(0.005)\end{array}$ & $\begin{array}{l}-0.001 \\
(0.004)\end{array}$ & 0.06 \\
\hline
\end{tabular}

Notes: Data from 2001 Parent Survey, and 2001 administrative records. Marginal probit coefficient estimates are presented, and each entry is the result of a separate regression. Robust standard errors in parentheses. Disturbance terms are clustered within schools. Significantly different than zero at $99(* * *), 95\left(^{* *}\right)$, and $90\left(^{*}\right)$ percent confidence. Social links controls and other controls are included in all specifications. Social links controls include total number of parent links, number of parent links to Group 1, 2, 3 schools (not own school), and number of parent links to non-program schools. Other controls include respondent years of education, community group member indicator variable, total number of children, iron roof at home indicator variable, and distance from home to school in $\mathrm{km}$, as well as the Group 2 indicator and Cost-sharing school indicator. The number of observations (parents) across regressions ranges from 1656 to 1678 depending on the extent of missing data for the dependent variable.

The ten possible infection symptoms (row 7) include fatigue, anemia, weight loss, stunted growth, stomach ache, bloated stomach, blood in stool, worms in stool, diarrhea, and fever. Parents were asked: "Could you name the symptoms of worm and schistosomiasis infections?”, and their responses were recorded by the enumerator. 


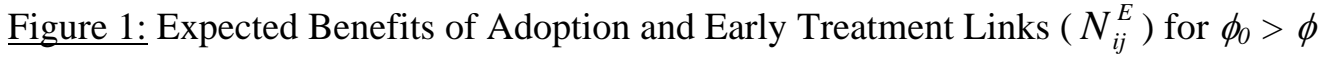

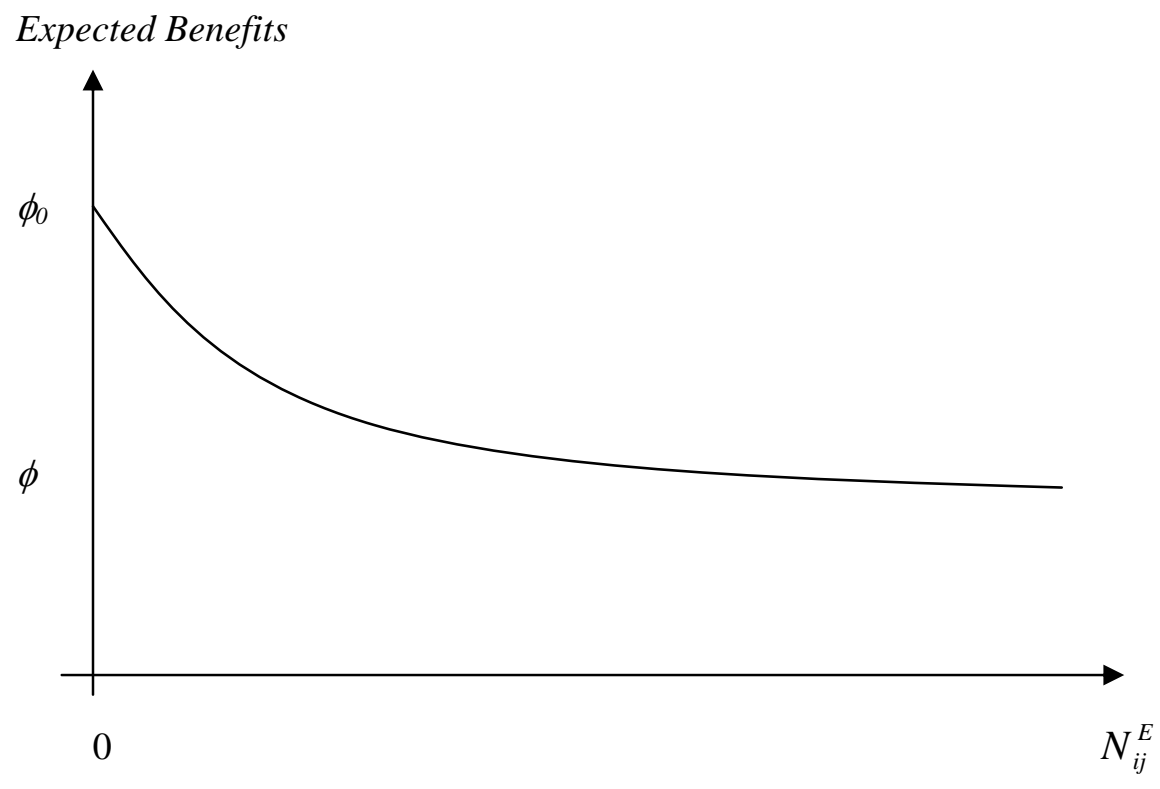

Figure 2: Non-parametric Fan regression (Epanechnikov kernel):

Effect of social links to early treatment schools (Group 1,2, not own school) on 2001 Deworming Drug Take-up (residuals conditional on other covariates)

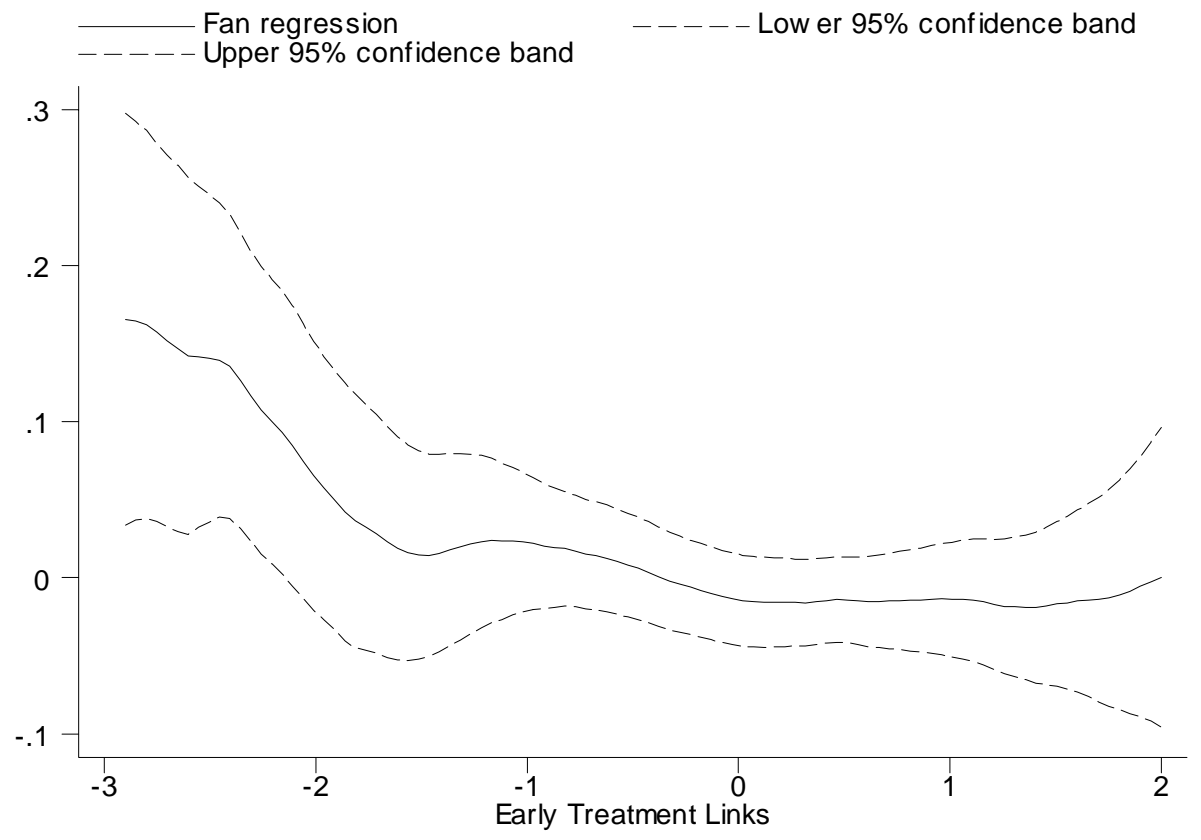




\section{$\underline{\text { Appendix }}$}

Appendix Table A1: Primary School Deworming Project (PSDP) timeline, 1998-2001

\begin{tabular}{|c|c|}
\hline Dates & Activity \\
\hline \multicolumn{2}{|l|}{1998} \\
\hline$\overline{\text { January }}$ & $\begin{array}{l}75 \text { Primary schools first stratified by geographic zone, and then randomly divided into } \\
\text { three groups of } 25 \text { schools (Group } 1,2,3 \text { ) }\end{array}$ \\
\hline March-April & First round of 1998 treatment (albendazole, praziquantel) in Group 1 schools \\
\hline November & Second round of 1998 treatment (albendazole) in Group 1 schools \\
\hline \multicolumn{2}{|l|}{1999} \\
\hline 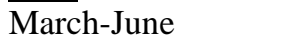 & First round of 1999 treatment (albendazole, praziquantel) in Group 1, 2 schools \\
\hline October-November & Second round of 1999 treatment (albendazole) in Group 1, 2 schools \\
\hline \multicolumn{2}{|l|}{2000} \\
\hline 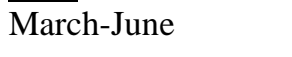 & First round of 2000 treatment (albendazole, praziquantel) in Group 1, 2 schools \\
\hline October-November & Second round of 2000 treatment (albendazole) in Group 1, 2 schools \\
\hline \multicolumn{2}{|l|}{2001} \\
\hline \multirow[t]{2}{*}{ 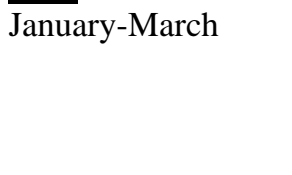 } & 2001 Parent Survey (Wave 1) data collection in Group 2, 3 schools \\
\hline & $\begin{array}{l}2001 \text { Pupil Survey (Wave 1) data collection in Group 2, } 3 \text { schools. Verbal commitment } \\
\text { intervention carried out during Pupil Survey, among a random subsample of pupils. }\end{array}$ \\
\hline March-June & $\begin{array}{l}\text { First round of } 2001 \text { treatment (albendazole, praziquantel) in Group 1, 2, } 3 \text { schools. Cost- } \\
\text { sharing in } 25 \text { (randomly selected) Group 1, } 2 \text { schools }\end{array}$ \\
\hline \multirow[t]{2}{*}{ May-September } & 2001 Parent Survey (Wave 2) and household GPS data collection in Group 2, 3 schools. \\
\hline & $\begin{array}{l}2001 \text { Pupil Survey (Wave 2) data collection in Group 2, } 3 \text { schools. Verbal commitment } \\
\text { intervention carried out during Pupil Survey, among a random subsample of pupils. }\end{array}$ \\
\hline October-November & $\begin{array}{l}\text { Second round of } 2001 \text { treatment (albendazole) in Group 1, 2, } 3 \text { schools. Cost-sharing } \\
\text { continues in } 25 \text { (randomly selected) Group 1, } 2 \text { schools }\end{array}$ \\
\hline
\end{tabular}


Appendix Table A2: Robustness of Social Effect Results - Parent Networks

\begin{tabular}{lcccc}
\hline \hline & \multicolumn{4}{c}{ Dependent variable: } \\
& \multicolumn{3}{c}{ Child took deworming drugs in 2001 } \\
& Probit & Probit & Probit & Probit \\
& $(1)$ & $(2)$ & $(3)$ & $(4)$ \\
\hline \# Parent links with children in early treatment schools & $-0.027^{*}$ & $-0.029^{* *}$ & $-0.071^{* * *}$ & -0.016 \\
(Group 1, 2, not own school) & $(0.014)$ & $(0.014)$ & $(0.023)$ & $(0.014)$ \\
\{\# Parent links with children in early treatment schools & & & $0.0064^{* *}$ & \\
(Group 1, 2, not own school)\} & & & $(0.0029)$ & \\
\# Pupils in early treatment schools $<3$ km from home & & & & $-0.20^{* * *}$ \\
(per 1000 pupils) & & & & $(0.07)$ \\
\# Pupils in all schools $<3$ km from home & & & & $0.14^{* *}$ \\
(per 1000 pupils) & & & & $(0.07)$ \\
Parent social links controls & & & & Yes \\
Other household controls & Yes & Yes & Yes & Yes \\
Ethnic, religious controls & No & Yes & Yes & Yes \\
\hline Number of observations (parents) & No & Yes & No & No \\
Mean of dependent variable & 1678 & 1678 & 1678 & 1678 \\
\hline \hline
\end{tabular}

Notes: Data from 2001 Parent Survey, and 1999 and 2001 administrative records. Probit estimation, robust standard errors in parentheses. Disturbance terms are clustered within schools. Significantly different than zero at $99(* * *)$, $95(* *)$, and $90\left(^{*}\right)$ percent confidence. Parent social links controls include total number of parent links, number of parent links to Group 1, 2, 3 schools (not own school), and number of parent links to non-program schools. Other household controls include respondent years of education, community group member indicator variable, total number of children, iron roof at home indicator variable, and distance from home to school in $\mathrm{km}$, as well as the Group 2 indicator and Cost-sharing school indicator.

Ethnic controls include indicators for Luhya-Samia, Luhya-Nyala, Luo, Luhya-Khayo, Luhya-Marachi, and Teso groups, and an indicator for being a member of the largest ethnic group in the school (which is near zero and statistically insignificant). Religion controls include indicators for Catholic, Anglican, Pentecostal, Apostolic, Legio Mario, Roho, and Muslim faiths, and an indicator for being a member of the largest religious group in the school (which is negative and marginally statistically significant). In regression 1, no household controls are included as explanatory variables other than the standard social link controls. 